\title{
Policy and Performance in Customs: Evaluating the Trade Facilitation Agreement*
}

\author{
Russell Hillberry ${ }^{\dagger}$ \\ Purdue University
}

\author{
Xiaohui Zhang \\ University of Essex
}

December 2016

\begin{abstract}
This paper links cross-country variation in trade facilitation policies to prominent indicators of national customs and logistics performance. We test the hypotheses that the policy data explain variation in the performance indicators, independent of other country characteristics that are plausibly exogenous to changes in trade facilitation policies. Because there are a large number of potential explanations for the performance outcomes we undertake a LASSO procedure in order to exclude variables that are not relevant for predicting customs performance. In general we find that country characteristics related to geography, income and the general quality of governance better explain cross-country variation in customs and logistics performance than do the measures of trade facilitation policy. The only policy variable with a robust relationship to an outcome variable that we study is an indicator for simplified procedures. Countries with simpler procedures have substantially lower total import times, as measured in the World Bank's Trading Across Borders Indicators.
\end{abstract}

Key words: Trade facilitation, World Trade Organization, LASSO, Multiple imputation JEL codes: F13, F14, F15

${ }^{*}$ The authors would like to thank Evdokia Moïsé and Silvia Sorescu of the OECD for providing us with the Trade Facilitation Indicator data, and Aaditya Mattoo and William Gain for inspiring the project, and Anton Yang for research assistance. Scott Baier, Caroline Freund, Selina Jackson, Marcus Johns, Aaditya Mattoo, Evdokia Moïsé, Gunjan Sharma, Silvia Sorescu and three anonymous referees who provided helpful feedback on earlier drafts. The research was partially funded by the governments of Norway, Sweden, and the United Kingdom through the Multidonor Trust Fund for Trade and Development.

${ }^{\dagger}$ Corresponding author. Department of Agricultural Economics, Krannert Building, Purdue University, West Lafayette IN, 47901; E-mail: rhillber@purdue.edu. 


\section{Introduction}

Under the terms of the 2013 Trade Facilitation Agreement (TFA), member countries of the World Trade Organization (WTO) are to commit to implementing a wide range of policies designed to reduce both the financial costs and the time required to accomplish international goods trade. ${ }^{1} \mathrm{~A}$ key feature of the TFA is a formal recognition that developing countries will be unable to fully implement the agreement without substantial technical and financial aid from developed countries. Aid-for-trade flows associated with the agreement will supplement the already large existing flows of development aid that are linked to trade facilitation reforms in developing countries. ${ }^{2}$

Among other good reasons, these large international aid flows make the monitoring of progress in trade facilitation extremely important. In this paper we study two sources of information on the performance of customs and trade logistics systems across the world. ${ }^{3}$ Both data sets are frequently used by the World Bank (and others) as broad indicators of national customs performance. The Trading Across Borders (TAB) data from the World Bank's Doing Business project report survey information on the time and financial costs associated with moving a representative shipment. The Logistics Performance Index (LPI), also collected and published by the World Bank, uses an alternative approach, publishing index measures of the performance of national trade logistics systems, including one subcomponent that focuses specifically on customs performance, more narrowly defined. It is likely that both sets of data will be used to assess both national and global progress in the area of trade facilitation. Both data sets are derived from surveys of logistics professionals, and thus should be understood as representing (informed) perceptions of customs performance, which may or may not represent actual cross-country differences in performance. ${ }^{4}$ These data nonetheless represent the best information about customs performance that is available globally on a consistent basis, and they are both used in policymaking as imperfect evidence of actual performance.

\footnotetext{
${ }^{1}$ As of this writing the agreement had not yet been ratified by the necessary $2 / 3$ of the WTO member nations, though there has been substantial progress toward that figure. As part of the ratification process member states spell out the conditions under which they will implement specific policies in the agreement.

${ }^{2}$ Over the five-year period 2010-2014, disbursements of overseas development assistance to support trade facilitation efforts in developing countries exceeded US $\$ 2$ billion. Author calculations using data from the OECD QWIDS database: https://stats.oecd.org/qwids/.

${ }^{3}$ Painting with a broad brush, we will use the shorthand 'customs performance' to summarize trade logistics outcomes that include several different types of activities. The activities of interest include clearance of traded goods by customs agencies and non-customs agencies with border authority, port and border processes, and in some cases transport. Another indicator summarizes system capabilities, such as the ability to track and trace goods or the ease of arranging competitively priced shipments.

${ }^{4}$ Even within a country, measures of customs performance exhibit extraordinary heterogeneity across products, firms, ports of entry, modes of shipment and countries of origin. The indicators we study attempt to summarize this heterogeneity with a small number of data points summarizing aspects of customs performance.
} 
The existing literature that employs these data has typically treated them as independent variables that explain other phenomena, especially trade flows. In this paper we treat the measures of national customs performance as outcomes that can be largely explained by other data. In broad terms the purpose of the study is to compare newly available data on trade facilitation policies against other potential explanations for cross-country variation in customs performance as measured by TAB and LPI data. The policy data that represent our variables of interest are the Trade Facilitation Indicators (TFI) collected by the Organization for Economic Cooperations and Development (OECD). The independent variables that we use as control variables fall into five categories a) country characteristics such as income, geography and institutional memberships (e.g. WTO, OECD) that are unlikely to be affected by changes in trade facilitation policies, b) broad measures of the overall quality of national governance (e.g. voice and accountability, rule of law), c) measures of trade infrastructure, d) control variables that relate to the relationship between the each country and its largest trading partner for export and for import shipments, respectively, and e) a vector of dummy variables that identify the broad type of a country's largest export product. $^{5}$

Estimation of the conditional effects of policy on the outcomes of interest poses a number of econometric challenges. One key problem is that the collection of the policy data itself is challenging, and so the TFI data are incomplete. In some countries, policy information is available for some indicators and not for others. Unfortunately, missing data are more common in poorer countries, where policy interest is greatest. To address this problem we employ well-established multiple imputation (MI) techniques to account for missing data. MI techniques provide consistent estimates of coefficients and standard errors, whilst taking into account the reality of missing data. ${ }^{6}$

A second estimation challenge relates to the large number of independent variables we include in the estimation. To the degree that the independent variables are correlated they may inflate standard errors or bias the associated coefficients. We address this problem in several ways. We conduct condition-number tests for multi-collinearity across our explanatory variables, finding that the policy variables themselves are only mildly collinear, but that the full vector of independent variables displays evidence of multicollinearity. We estimate empirical models without the policy data to highlight a central lesson of our study: that the trade facilitation outcomes we study can

\footnotetext{
${ }^{5}$ These latter two sets of variables are important as controls for the TAB regressions because the underlying surveys for that data relate to a specific shipment to/from a specific trading partner. We also include these variables in our estimation of the LPI data but find little evidence that they are relevant for the LPI indexes.

${ }^{6}$ The estimates are, of course, dependent on both the imputation and the estimating models. We discuss MI assumptions in some detail when we describe our methods.
} 
largely be explained by underlying country characteristics that are not likely to be affected by the TFA. We then estimate empirical models that include all the explanatory variables, and use these regressions to conduct exclusion tests for relevant sets of variables. Finally we implement a least absolute shrinkage and selection operator (LASSO) (with multiple imputation) in order to systematically choose the variables that best explain variation in the outcome data.

In broad terms our work indicates that both the TAB and LPI outcome data can largely be explained by variables other than those representing trade facilitation policies. This appears to be especially true of the LPI data, which is very well explained by country characteristics such as economic size, and by an additional set of variables that measure countries' general quality of governance (not in customs specifically, but across all aspects of civic life). The TFI data alone can explain about half of the variation in the LPI data, but our estimates suggest that the TFI data add little or no additional information that is useful for predicting LPI outcomes once the other explanatory variables enter the regression. The TAB data are less well explained by general measures of governance, but depend heavily on each country's relationship to its major trading partner (which is identified in the underlying surveys summarized in the TAB). We do find some evidence that TAB measures of import time are affected by the TFI data. Across multiple specifications of the LASSO model the coefficient on the TFI variable measuring the simplicity of procedures is statistically significant and negative in our models of import time. When we apply these estimates in a counterfactual exercise we find that improving procedures could produce substantial reductions in total time to import.

The paper proceeds as follows. Section 2 provides a review of the relevant empirical literature on trade and logistics. Section 3 describes the data, especially the measures that describe border outcomes and the quantitative representations of border management procedures. Section 4 describes the estimating framework. Section 5 provides the estimation and counterfactual results.

\section{Literature}

Our exercise uses a relatively new source of data on trade facilitation policies (the TFI data) to study more established measures of customs performance (the TAB and LPI data). A small number of recent papers use the TFI as we do, as independent variables that explain other phenomena. A larger literature uses the TAB and LPI data, though typically in a somewhat different manner. We 
treat these data as outcome variables, even though they are more commonly used as independent variables. We review the larger literature that uses our outcome data as independent variables. We also summarize a more recent literature that evaluates specific reforms in specific countries using detailed data from national customs authorities.

\subsection{Studies using TFI data}

The relatively recent provenance of the TFI data mean that the number of papers using them is still quite small. Moïsé et al. (2011) provide a description of the first subset of TFI data, those collected from OECD member countries alone. The authors use the TFI data as independent variables in gravity regressions with bilateral sector-level trade flows and with inferred trade costs as independent variables. They find that the TFI variables that most affect these outcomes in OECD countries are advance rulings, information availability, procedures and inter-agency cooperation. Moïsé and Sorescu (2013) describe the collection of TFI data in developing countries. Since there are more significant challenges to the collection of policy data in developing countries, Moïsé and Sorescu (2013) construct TFI data using fewer inputs, and they describe their procedures for constructing the indicators in the face of missing input data. The authors perform similar econometric analyses as in Moïsé et al. (2011), but apply it to developing country data. Among other findings, these authors estimate that the most significant TFI variables in terms of predicting trade flows are information availability, harmonisation and simplification of documents, automation, streamlining of border procedures and good governance and impartiality.

Fontagnét et al. (2016) use data from French firms to study the heterogeneous effects of policy variation in the TFI data on firm-level exports. They interact exporter size-bin dummies with individual TFI variables and find heterogeneous effects across firms sizes of the TFI policy bundles on export value and export composition. They conclude that better information availability, advance rulings and appeal procedures in a destination country disproportionately benefit small firms, while simplification of documents and automation tend to favor large firms. They consider the various TFI indicators in separate regressions, making it difficult make inferences about the conditional effects of variation in a given TFI policy variable.

Beverelli et al. (2015) estimate the effect of the within-country average of TFI data on export diversification. Specifically, the outcomes they study are the extensive margins of new export destinations per product and new products per export destination. They find significant effects of the 
average TFI score on these margins. They also employ TAB data as independent variables and find significant effects of average TFI on export diversification. In order to provide an estimate of the impact of the TFA, the authors conduct counterfactual exercises that move countries with average TFI below their regional medians to the regional median. They estimate regional increases in product and trading partner diversity of between $4 \%$ and $27 \%$ as outcomes of this particular scenario.

As in these four papers, we study the effect of TFI variables on outcome variables, though the outcome variables we study are different. Our outcome, customs performance, is intermediate for the trade outcomes other authors study, and may suggest one channel through which their effects are observed. Like Moïsé et al. (2011) and Moïsé and Sorescu (2013), we consider all of the TFI variables jointly, rather than individually (like Fontagnét et al. (2016)) or as an average (like Beverelli et al. (2015)). Our outcome variables are survey responses, so we include a broader set of control variables in our estimates. Unlike other authors using TFI data we apply multiple imputation to account for non-random sources of missing data. We apply LASSO techniques to improve parsimony, combining MI with these techniques to increase the number of degrees of freedom.

\subsection{Studies using customs performance data}

Most of the literature that relates to our work treats TAB and LPI data as independent variables in an econometric model in which the dependent variable is the value of trade or some other traderelated outcome. We differ in that we treat these variables as dependent variables, and attempt to explain them with other data including the OECD policy data. It is nonetheless useful to review the literature with the customs performance variables on the right hand side.

Most of the empirical literature using TAB data to study international trade uses the time-totrade measures rather than estimates of the monetary costs of trading. This is true of the initial study using these data, Djankov et al. (2010), which focuses its attention on a single component of the TAB indicators, days spent in inland transit. Using a modified gravity regression, Djankov et al. (2010) estimate that a one-day increase in inland transport times reduces exports by approximately one percent. Subsequent regressions indicate that exports of time sensitive goods are more sensitive to inland transit time than are other goods. ${ }^{7}$

Subsequent studies using these and related data have linked longer trading times to reduced trade and to other negative outcomes. Freund and Rocha (2011) investigate the impact of three

\footnotetext{
${ }^{7}$ Djankov et al. (2010) also provides a useful review of the TAB time-to-trade data that we use.
} 
subcomponents of the TAB data on exports, finding that the inland transit time variable was most robustly associated with lower levels of African exports. ${ }^{8}$ Hornok and Koren (2011) link subcomponents of the TAB data to larger and less frequent import shipments. Li and Wilson (2009) link the total time-to-export measure to firm-level data and find that producers of time-sensitive goods are less likely to become exporters in countries where the TAB time-to-export measure is larger.

A number of other recent studies use LPI and other World Bank data as independent variables. Saslavsky and Shepherd (2014) show that trade in parts and components is more sensitive to the LPI than are other goods. Shepherd (2013) and Hoekman and Shepherd (2013) use data on reported time-to-trade from the World Bank's Enterprise Surveys as an independent variable predicting export shares. Shepherd (2013) shows that firms with shorter border clearance times export more, while Hoekman and Shepherd (2013) show that the effects of border clearance times on exports do not differ across firm sizes.

\subsection{Impact evaluation studies of customs reform}

Our work lies within the tradition that employs cross-sectional regressions to infer likely effects of trade facilitation policies on trade outcomes. Of course, cross-sectional regressions cannot credibly establish causal mechanisms. A recent literature uses the detailed data available from national customs authorities in an attempt to isolate causal effects over a reform episode. Other studies use the data to better understand links between trading time and trade volumes. Contributions to this literature include Carballo et al. (2016a), Carballo et al. (2016b), Carballo et al. (2016c), Carballo et al. (2016d), Fernandes et al. (2015), Fernandes et al. (2016) and Martincus et al. (2015). This is a very interesting literature, but the results of any one study are highly contextual, depending on the specific circumstances of the country or countries of study and the specific nature of the reform. Relative to this literature we view our study as a complement that informs global relationships between trade facilitation policies and customs performance.

\section{Data}

Our estimation exercises employ three types of data. The first type that we describe are the relatively new TFI data documenting trade facilitation policies across the world. Our primary interest is in

\footnotetext{
${ }^{8}$ Hornok (2012) uses a measure of time-to-trade that does not come from the TAB data - truck waiting times at European borders - as an explanatory variable for trade outcomes.
} 
the effects of these policy variables on customs performance, and we therefore describe these data in some detail. The second type of data are the outcome variables we study, two groups of indicators of national performance in the area of customs and trade logistics. Because the TAB have been overhauled recently we describe these in somewhat greater detail than the LPI. The third set of data are control variables that may also affect the outcome variables, independent of policy. We describe each set of data in turn.

\subsection{Quantitative measures of border policy}

The primary goal of this paper is to relate cross-country variation in trade facilitation policies and procedures to other data documenting the performance of national trade logistics systems. Heretofore this has been a difficult issue to address empirically because quantitative representations of border policies/procedures have not been available. ${ }^{9}$ In anticipation of the Bali negotiations the OECD set out to correct this problem, identifying 12 categories of trade facilitation policies and procedures reflected in the text of the TFA. After documenting national policies and procedures, the OECD scored countries on their proximity to the world's best practice in each of the policy categories. The OECD's initial TFI estimates reported scores for all 12 policy bundles. In this draft we use data from the (2015) second round of data collection. In the second round the OECD dropped one of the twelve original policy groups, consularization, leaving us with 11 trade policy variables to study. ${ }^{10}$

The raw material for the OECD's 11 trade facilitation indicators is a detailed catalogue of trade facilitation policies and procedures around the world. For example, one question asks whether necessary documents can be downloaded from the website of the customs agency. The OECD's initial catalogue, based in 2010, attempted to document 95 such indicators in OECD countries. A subsequent catalogue, representing the situation in 2012, attempted to track 78 procedures in nonOECD countries. The OECD dropped 7 questions because insufficient information was available. Among the remaining 71 procedures, countries were scored 0 (worst), 1, or 2 (best). A country's scores on the individual components were averaged within each of the categories to produce policy

\footnotetext{
${ }^{9}$ The outcome measures we study from TAB and LPI provide some high-level information. But these do not represent the breadth of the policy reforms considered in the TFA, nor do they provide sufficient policy detail for our purposes.

${ }^{10}$ Consularization is a requirement that a consular invoice or consular visa be obtained to accompany other international trade documents. In the first round of the TFI consularization was the most commonly missing data point. Our earlier study of these data, Hillberry and Zhang (2015), found no statistically significant effect of consularization on any of the outcome variables that we studied.
} 
scores at the country-indicator level.

The policy scores summarize information about 11 different areas of border policy: Information availability, Involvement of the trade community, Advance rulings, Appeal procedures, Fees and charges, Formalities regarding documents, Formalities regarding automation, Formalities regarding procedures, Border agency cooperation - internal, Border agency cooperation - external, and Good governance and impartiality. ${ }^{11}$ Appendix Table A1 provides a comprehensive listing of the policy inputs, and links each to one of the policy bundles. The policy bundles are each related to one or more articles of the draft negotiating text that formed the basis of the TFA. ${ }^{12}$ In our analysis, we use the OECD's reported score for each of the 11 policy bundles that remain in the second tranche of data, and interpret each variable as the quantitative measure of border policy in that category.

Before moving to our analysis we adjust one of the variables, formalities regarding documents, to address a possible endogeneity concern. Four of the six inputs the OECD used to construct this variable are taken from a prior TAB survey. While the variables the OECD used as inputs are not the same variables that appear on the left hand side of our estimation model, the construction of TAB data from survey responses makes it possible that our outcome variables and these data inputs are endogenous. ${ }^{13}$ To address this concern we regress the formalities regarding documents variable on the four TAB inputs used by the OECD, and construct a new measure of the documentation burden from the constant and the error terms from this regression. ${ }^{14}$ This procedure purges any possible endogeneity that would arise from the OECD's use of TAB data as inputs. ${ }^{15}$

While the OECD has scored most policies for most countries, they do not report a score in those country-indicator pairs where the available information is not adequate to produce a score. These missing scores reflect an inability to collect complete data at the level of the underlying subindicators. Moïsé and Sorescu (2013) explain in their Annex 1 that TFI scores are not reported for indicator-country pairs for which less than $40 \%$ of the subcomponents are missing. Table 1 offers a short summary of the quality of the indicator data. The policy data are particularly lacking in the

\footnotetext{
${ }^{11}$ We italicize the shorthand name for each variable as it appears in subsequent tables. Policy bundle names are shortened to save space.

${ }^{12}$ Moïsé and Sorescu (2013), p.9 illustrates these links.

${ }^{13}$ Because TAB surveys many of the same respondents from year to year there is a possibility across samples if respondents who report high levels of documentation required also report long import clearance times or high import clearance costs.

${ }^{14} \mathrm{By}$ construction, the correlation between the new variable and the TAB data is 0.00 . The correlation of our purged Documents variable with the initial Documents variable reported by the OECD is 0.579.

${ }^{15}$ The OECD also uses LPI data as inputs into its policy variables, but all of these appear to be taken from the 'domestic' LPI rather than the 'international' LPI that provides the indices we study. The domestic and international LPI survey different respondents and ask different questions. We therefore do not apply any preadjustment to the TFI data that use LPI data as inputs.
} 
Table 1: Trade Facilitation Indicators: Summary statistics

\begin{tabular}{llllll}
\hline Variable & Obs & Mean & Std. Dev. & Min & Max \\
\hline Information availability & 161 & 1.38 & 0.51 & 0 & 2 \\
Involvement of the trade community & 154 & 1.23 & 0.52 & 0 & 2 \\
Advance rulings & 158 & 1.06 & 0.69 & 0 & 2 \\
Appeal procedures & 150 & 1.34 & 0.47 & 0 & 2 \\
Fees and charges & 150 & 1.23 & 0.46 & 0 & 2 \\
Documents & 160 & 1.38 & 0.27 & 0.59 & 2 \\
Automation & 161 & 1.16 & 0.55 & 0 & 2 \\
Procedures & 161 & 1.09 & 0.35 & 0.22 & 1.87 \\
Cooperation - internal & 152 & 1.24 & 0.59 & 0 & 2 \\
Cooperation - external & 123 & 1.07 & 0.77 & 0 & 2 \\
Good governance and impartiality & 152 & 1.18 & 0.62 & 0 & 2 \\
\hline Not: Srata
\end{tabular}

Note: Summary statistics for policy data describe in the text. Documents data adjusted as described.

area of border agency cooperation (external), but other policies also have missing data. ${ }^{16}$ Discarding countries with incomplete policy data from the sample would mean discarding a substantial amount of useful policy data, as many countries have some policy data even though the policy data is not complete. Moreover, discarding countries with incomplete data would bias the sample towards countries with more transparent (and, usually, better) policy. This situation motivates our use of multiple imputation techniques, which we describe later in the paper.

\subsection{Measures of customs performance}

The outcome variables that we study are six country-level indicators of performance in customs and other aspects of trade logistics. The measures are taken from two distinct World Bank efforts to rate/rank the quality of national logistics and border management systems responsible for the movement of goods in international trade. Both efforts rely on surveys of logistics professionals, but the format of the questions, the respondent sample for each survey, and the outputs of the survey differ across the two approaches. The Trading Across Borders survey, collected under the World Bank's Doing Business framework, attempts to quantify specific outcomes (US dollar costs and time requirements) associated with the assembly of documentation, port handling activities, and clearance by customs and other border agencies of a hypothetical (but typical) international shipment for each country. The Logistics Performance Index reports outcomes that are more abstract, asking

\footnotetext{
${ }^{16}$ The quality of the data in the second round of TFI collection is much better than in the first round. In the 2015 data, the number of available observations per indicator ranges from 123-161 (see Table 1), while Table 1 in Hillberry and Zhang (2015) shows a range of 73-132 in the 2010-2012 TFI data.
} 
respondents to rate aspects of national logistics systems on a 5-point scale and summarizing responses across multiple questions in an index measure. We review each of these outcome variables in turn, paying more attention to the Trading Across Borders estimates because the most recent TAB data have undergone a significant shift in the data collection methodology.

\subsubsection{Trading Across Borders survey from Doing Business}

The World Bank's Doing Business survey is an attempt to provide reliable cross-country information on the monetary and time costs of various private sector activities across the world. The TAB data we use are from the subcomponent of the Doing Business project that focuses on international trade shipments. Specifically, the survey asks about the time and cost associated with moving a 15 metric ton shipment of a common product valued at US $\$ 50,000$ to (or from) the country's largest city from (or to) a warehouse inside the country that is the largest trading partner for the traded product in question. Like other components of the Doing Business project, the TAB survey has recently undergone a substantial overhaul. Since we are one of the first to use these data following the overhaul, we describe them in some detail.

There are five main differences between the new (2016) TAB data and older versions of the data that affect our work. First, the new TAB data report units of time in (fractional) hours rather than in the large discrete units (days) used in the earlier surveys. This substantially simplifies our estimation problem, relative to the older survey. Second, the survey now avoids double counting activities that an international trader can undertake concurrently (e.g. waiting for clearance from customs and from non-customs agencies). Third, the subcomponents of trading activities studied in the TAB have been redefined. ${ }^{17}$ Fourth, the hypothetical import shipment described in the TAB survey now has a uniform imported product (HS 8708 - auto parts), while the export product described in the survey is the country's largest export product. ${ }^{18}$ Fifth, the hypothetical source for import shipments and hypothetical destination for export shipments is the largest trading partner for each type of shipment, rather than the nearest ocean port as in the older TAB surveys. One of the key reasons for this latter change was that the prior survey implied very long reported trading times for landlocked countries, as the hypothetical ocean-bound shipment was required to travel

\footnotetext{
${ }^{17}$ So, for example, the prior survey reported separately the time required for assembling documentation. But documentation requirements have now been allocated across several sets of activities, including customs clearance, clearance from other agencies, and port or border clearance time.

${ }^{18}$ If the country's largest export product is precious metal or gems, mineral fuels, oil products, live animals, residues and waste of foods and products or pharmaceuticals, TAB uses the second largest export product.
} 
great distances and cross multiple borders en route to the sea. An additional change in the new survey is that the TAB reports some data at a sub-national level. We do not exploit this variation, as our policy and other data are only available at the national level.

In total the TAB survey reports 18 variables that describe some component of the time and cost required to accomplish an international trade shipment. For both exports and imports there are five measures of time: customs, customs + other agencies, time at the port or border, time outside the port or border for administrative activities, and the total time required to export or import the hypothetical shipment. In the interests of space we study TAB's most inclusive measure of compliance time, which includes the time required for documentation, clearance by customs and non-customs agencies, and time at the port or border. For both imports and exports TAB reports four cost outcomes: cost of clearing customs, cost of clearance by non-customs agencies, cost of port or border procedures, and total cost. We choose total cost as the most useful cost metrics for our purposes from TAB. ${ }^{19}$

\subsubsection{Logistics Performance Index (LPI)}

The LPI offers an alternative to the TAB as a set of high-level indicators of country-level performance among several trade logistics activities. The LPI project itself contains two subcomponents: the 'domestic' LPI survey that gathers information from trade logistics professionals about the situation in their own countries, and the 'international' LPI that surveys foreign trade logistics professionals about the relative performance of countries with which they trade. Our focus in this paper is the international LPI, because it provides a metric by which countries' performance can be scored.

The international LPI is an index measure that is composed of six component inputs, each of which measures a particular aspect of trade logistics performance in the country. Of particular interest to this study is the 'customs' subcomponent of the LPI, and we study this variable itself as an outcome. We choose customs LPI because it is plausibly amenable to TFA reforms, and likely to be dependent on a broader range of the proposed TFA reform measures. The 'overall' LPI is an even broader measure of customs performance, and we take this as a proxy for other aspects of trade and customs performance thought to be important by the designers of the LPI. The overall LPI index is calculated as the first eigen vector of a principal components analysis of the six inputs. Arvis et al.

\footnotetext{
${ }^{19}$ We also estimated using on the reported times and costs at the port or border. These variables capture time and costs while the goods are in transit, and we view the time spent at the port or border as especially salient for trading firms because the shipment is underway at that point. The results from these exercises were quite similar to the results for total time and cost, except that the effects of policy were even weaker.
} 
(2016) show that this principal component summarizes 94 percent of the overall variation in the six LPI subcomponents. This implies a very high degree of correlation among the subcomponents and between the overall index and each of the subcomponents. ${ }^{20}$

\subsection{Other independent variables}

In order to isolate the effect of policy on the performance of customs we must also include other control variables that could affect customs performance. In particular we wish to include variables that are exogenous to changes in the specific policies outlined in the TFA, but still plausibly predictive of the survey information on the border outcomes that we study. We consider five sets of control variables: a set of broad controls that summarize countries' level of development, size, geography and membership in international institutions; a second set of variables that summarize the quality of national governance; a third set of variables that control for the quality of trade-related infrastructure; a fourth set includes dummy variables denoting geographical and policy relationships between the country of interest and its main trading partner; and a fifth set of dummy variables that control for broad differences in the type of product defined as the countries' principal export product in the TAB surveys.

\subsubsection{Basic control variables}

The first set of control variables includes levels of development, geographical indicators, and membership in relevant international economic organizations. These variables might be expected to affect both the level of international trade and the performance of border agencies. One key determinant of the performance of border agencies is likely to be the country's level of economic development, which might affect performance through factors such as the educational attainment of agency officials, the capabilities of the firms engaged in international trade, and the quality of the infrastructure at the border, among other possibilities. We measure levels of development flexibly, including log per capita GDP and squared log per capita GDP on the right hand side. We also include a log GDP measure to control for variation in the overall size of the economy. The underlying data for these measures are taken from the 2011 World Development Indicators. ${ }^{21}$

\footnotetext{
${ }^{20}$ Our results below show that the variables that best predict the LPI 'customs' index are very similar to those that predict the overall LPI index. This is consistent with customs LPI being highly correlated with the overall LPI, and, by implication, with the other 5 components of the LPI.

${ }^{21}$ More recent data are incomplete.
} 
We include three measures of geography. Logged square kilometers is our measure of country size, and is also taken from the World Development Indicators. It may be that larger countries trade less and so have less developed customs agencies. We include dummy variables that indicate if a country is landlocked or if it is an island. These data are taken from the French research institute CEPII. The landlocked dummy may capture variation in performance arising from movement across neighboring countries, or may indicate a lack of better trading options more generally.

We include dummy variables that indicate a country's membership in either the OECD or the World Trade Organization (WTO). These data are taken from the respective organizations' web sites. The OECD dummy acts as an additional indicator of development, but the institution itself may be responsible for better outcomes in its member states. WTO membership might be thought to affect trade volumes in a manner that is independent of customs performance.

We also include, in the estimates we report, a measure of trade openness, which is calculated as the value of exports plus imports (of merchandise) divided by GDP. We use 2011 data from the World Development Indicators to achieve maximal completeness of this variable. ${ }^{22}$ Because trade facilitation policy and openness are persistent, even lagged openness is potentially endogenous to trade facilitation policy measures, so we also run all of our specifications without the openness variable. $^{23}$

\subsubsection{General measures of governance}

We use the TFI variables to estimate the effect of border policy, specifically, on perceptions of customs performance. These perceptions might also be driven by the overall quality of governance in the country. Since we are trying to isolate the effect of policy in customs, we also include measures of the quality of broad governance in each country as control variables. Our source for these data are the Worldwide Governance Indicators (WGI), as described in Kauffman et al. (2010).

There are five WGI variables. Voice and Accountability quantifies the ability of a country's citizens to participate in the selection of the government, as well as related freedoms such as freedom of speech. Political Stability and Absence of Violence/Terrorism measures the degree to which political violence threatens the stability of the government. Government Effectiveness is an indicator of the perceived quality of public services, the civil service, and related matters. Regulatory Quality

\footnotetext{
${ }^{22}$ The World Development Indicators do not include Taiwan, so we supplement with information from the CIA World Fact book in the case of Taiwan.

${ }^{23}$ Excluding openness affects the magnitudes of other variables but does not materially affect their sign nor levels of significance.
} 
measures the quality of regulations that permit and promote private sector development. Control of Corruption is the perceived influence of corruption on governance, including capture of the state by elites and private interests. These variables are all increasing with the quality of governance, and we expect them to reduce clearance times.

We will soon demonstrate that the governance variables are correlated with the TFI measures of policy, and this is not surprising. For example, the efficacy of appeal procedures related to decisions by the customs agency might depend not only on policies at the customs agency, but by the countries' court system. The TFI variable measuring involvement of the trade community in decisions by the customs agency may be less relevant than more general measures of voice and accountability in policymaking. TAB and LPI survey respondents might take into account the countries' more general qualities of governance when they respond about issues related to the movement of goods through customs. $^{24}$

\subsubsection{Trade infrastructure variables}

The final set of variables we include as potential controls are measures of trade infrastructure taken from Portugal-Perez and Wilson (2012). These authors construct four variables that are intended to measure aspects of the quality of trade infrastructure. The fourth of these, Border and Transport Efficiency is constructed with inputs that are entirely from the (previous) TAB database, and are also closely related to policies contained in the TFA (documents required for trading, and days required for trading). We therefore exclude that variable but consider the other three trade infrastructure variables in our estimation procedure.

Physical Infrastructure is an indicator of the quality of the relevant transport infrastructure, including ports. Information and Communications Technology (ICT) summarizes information on the absorption and use of technology in a country's private sector and in government. The Business Environment variable summarizes indicators of government transparency, public trust, and corruption. Portugal-Perez and Wilson (2012) construct these variables for only 112 of the countries/territories that we include in our sample so we use multiple imputation for these variables as well.

\footnotetext{
${ }^{24}$ This might be especially true of the LPI index, which relies on trade logistics professionals outside the country, who may be involved only infrequently in shipments to the country in question, and default to a heuristic sense of the broader qualities of governance in the country that is the focus of the survey.
} 
Table 2: Other variables - summary statistics

\begin{tabular}{lcllll}
\hline Variable & Obs & Mean & Std. Dev. & Min & Max \\
\hline \multicolumn{7}{c}{ Outcome variables } \\
Trading Across Borders & \multicolumn{7}{c}{$\begin{array}{l} \\
\text { Total time to import (hours) }\end{array}$} & 183 & 85.60 & 129.87 & 0 & 1330 \\
Sum of import costs (USD) & 183 & 467.70 & 388.27 & 0 & 2089 \\
Total time to export (hours) & 183 & 62.69 & 83.45 & 0 & 816 \\
Sum of export costs (USD) & 183 & 389.35 & 329.27 & 0 & 1975 \\
Logistics Performance Index & & & & & \\
LPI customs index & 156 & 2.73 & 0.63 & 1.11 & 4.18 \\
LPI overall index & 156 & 2.90 & 0.62 & 1.60 & 4.23 \\
\hline
\end{tabular}

\section{Country characteristics}

log openness 2011

GDP per capita 2011 (USD)

GDP (2011)

Landlocked

Island

WTO

OECD

Land Area (ln square km)

Governance Indicators

Control of Corruption

Effectiveness

Stability

Regulatory Quality

Voice and Accountability

Independent variables

Trade Infrastructure

Infrastructure

ICT

Business Environment

$\begin{array}{lllll}180 & 4.45 & 0.48 & 3.17 & 6.10 \\ 183 & 14066 & 20092 & 237.16 & 115377 \\ 183 & 382382 & 1378888 & 182.31 & 1.50 \mathrm{E}+07 \\ 183 & 0.20 & 0.40 & 0 & 1 \\ 183 & 0.25 & 0.43 & 0 & 1 \\ 183 & 0.85 & 0.36 & 0 & 1 \\ 183 & 0.18 & 0.39 & 0 & 1 \\ 183 & 11.40 & 2.56 & 4.09 & 16.65\end{array}$

Import partner dummies

Land Border

PTA or CU

Export partner dummies

Land Border

PTA or CU

Export product dummies

Animal, veg or food

$\begin{array}{lllll}183 & -0.04 & 0.98 & -1.84 & 2.27 \\ 183 & -0.01 & 0.96 & -2.03 & 2.19 \\ 183 & -0.04 & 0.93 & -2.76 & 1.49 \\ 183 & 0.00 & 0.95 & -2.19 & 2.23 \\ 183 & 0.02 & 0.95 & -1.98 & 1.71\end{array}$

Chem, plastics or rubbers

112

$112 \quad 0.54$

0.24

$0.10 \quad 1$

$112 \quad 0.42$

0.23

$0.12 \quad 1$

$183 \quad 0.39$

0.26

$0.01 \quad 1$

Hides, skins, textiles and footwear

Wood products

$183 \quad 0.56$

0.49

$\begin{array}{ll}0 & 1\end{array}$

183

$\begin{array}{ll}183 & 0.36\end{array}$

0.50

0

1

$183 \quad 0.53$

0.48

$0 \quad 1$

$183 \quad 0.35$

0.50

0

1

$\begin{array}{ll}183 & 0.13\end{array}$

0.48

$0 \quad 1$

$\begin{array}{ll}183 & 0.09 \\ 183 & 0.02\end{array}$

0.33

0

1

0.28

0

$183 \quad 0.13$

0.13

0.33

$\begin{array}{ll}183 & 0.23\end{array}$

0.42

$\begin{array}{ll}183 & 0.05\end{array}$

0.23

$\begin{array}{lll}183 & 0.01 & 0.10\end{array}$

1

Metals

Machinery and electronics

Transport

$\begin{array}{ll}0 & 1\end{array}$

Misc and services

0.01

Note: Summary statistics for outcome variables of interest and for independent variables (TFI variables excepted). GDP per capita and GDP are logged prior to their inclusion in empirical work. 


\subsubsection{Main trading partner and principal export product dummies}

We include additional geography and policy variables that describe each country's relationship to its largest trading partner (on the import and export side, respectively). The identity of the largest trading partner is included directly in the TAB survey. The hypothetical import shipment used in the survey contains auto parts. For each country we identify the largest source country for auto parts, and create one dummy variable that indicates whether or not that country shares a land border with the country of interest, and another dummy variable indicating that the two countries are part of a preferential trade agreement or a customs union. On the export side, the hypothetical shipment contains the country's largest export product (excluding a number of products such as oil), and is shipped to a destination country that is the largest importer of the product from the country of interest. We also create dummy variables indicating whether the paired destination country shares a land border with the country of interest and another indicating whether or not the two countries are joint members of a PTA/customs union. Since the nature of the export product might also affect clearance time or cost, we also include a dummy variable indicating the broad category of export products in which the country of interest's export product falls. The broad export categories for which there are dummy variables are reported in Appendix Table A2.

\subsubsection{Correlation of TFI and control variables}

One of the challenges that we face in estimating our empirical models is the potential for multicollinearity amongst the many control variables we include in the estimation. As an initial check on this, we report in Table 3 the pairwise correlations amongst all the TFI variables, as well as pairwise correlations between the TFI variables and other control variables that are highly correlated with the TFI variables. For space reasons we omit those variables without a single pairwise correlation with the TFI variables that is larger than 0.5 in absolute value. ${ }^{25}$

The results of this work show that there is some cause for concern about multicollinearity. Although there are no correlations greater than 0.68 , there are a reasonably large number of correlations greater than 0.5. Amongst the TFI variables, TFI data summarizing Appeal procedures, Advance rulings, Good governance, Information availability, and Involvement of the trade community are frequently correlated with other TFI data.

\footnotetext{
${ }^{25}$ Note that we have not at this point imputed any data, so the pairwise correlations are those that apply only to data reported by the OECD.
} 
Moving to correlations between the TFI variables and other control variables, we see that TFI scores for appeal procedures are frequently correlated with the governance indicators, the trade infrastructure variables, and with GDP per capita measures. This seems plausible, as countries with good governance generally are likely to have higher per capita incomes and to have well established appeal procedures in the general legal system, which would likely spill over into efficient and effective appeal procedures in the customs environment. From an econometric point of view these high correlations can make it difficult to identify a separate impact of appeal procedures on customs performance. But from a policy evaluation point of view this ambiguity offers an important insight. It may, in fact, be difficult for the TFA to generate transparent and effective appeal procedures for decisions by the customs agency without corresponding improvements in governance more broadly within a country.

\subsubsection{Condition number analysis}

The correlation matrix in Table 3 suggests that multicollinearity may be a concern, but it is not definitive. A standard method for testing for the presence of multi-collinearity is the condition number test (Belsley et al. (1980)). The condition number provides a quantitative measure of the numeric difficulties associated with inversion of the matrix of right hand side variables. ${ }^{26}$ Standard rules of thumb suggest that condition numbers in excess of 30 indicate a significant risk for multi-collinearity. Belsley et al. (1980) suggest an additional analysis that decomposes the share of variation in implied regression coefficients that can be linked to specific eigen vectors. A joint combination of a high condition index for an eigen vector and high values (usually 0.5 or more) in the decomposition results linked to that eigen vector would suggest a high risk of multicollinearity.

\footnotetext{
${ }^{26}$ Each eigen vector associated with a principal components analysis of the data in question has an associated eigen value. The condition index for each eigen vector is the square root of the ratio of the maximum eigen value for the matrix and the eigen value associated that eigen vector. The condition number is the maximum value of the condition index for the entire matrix.
} 


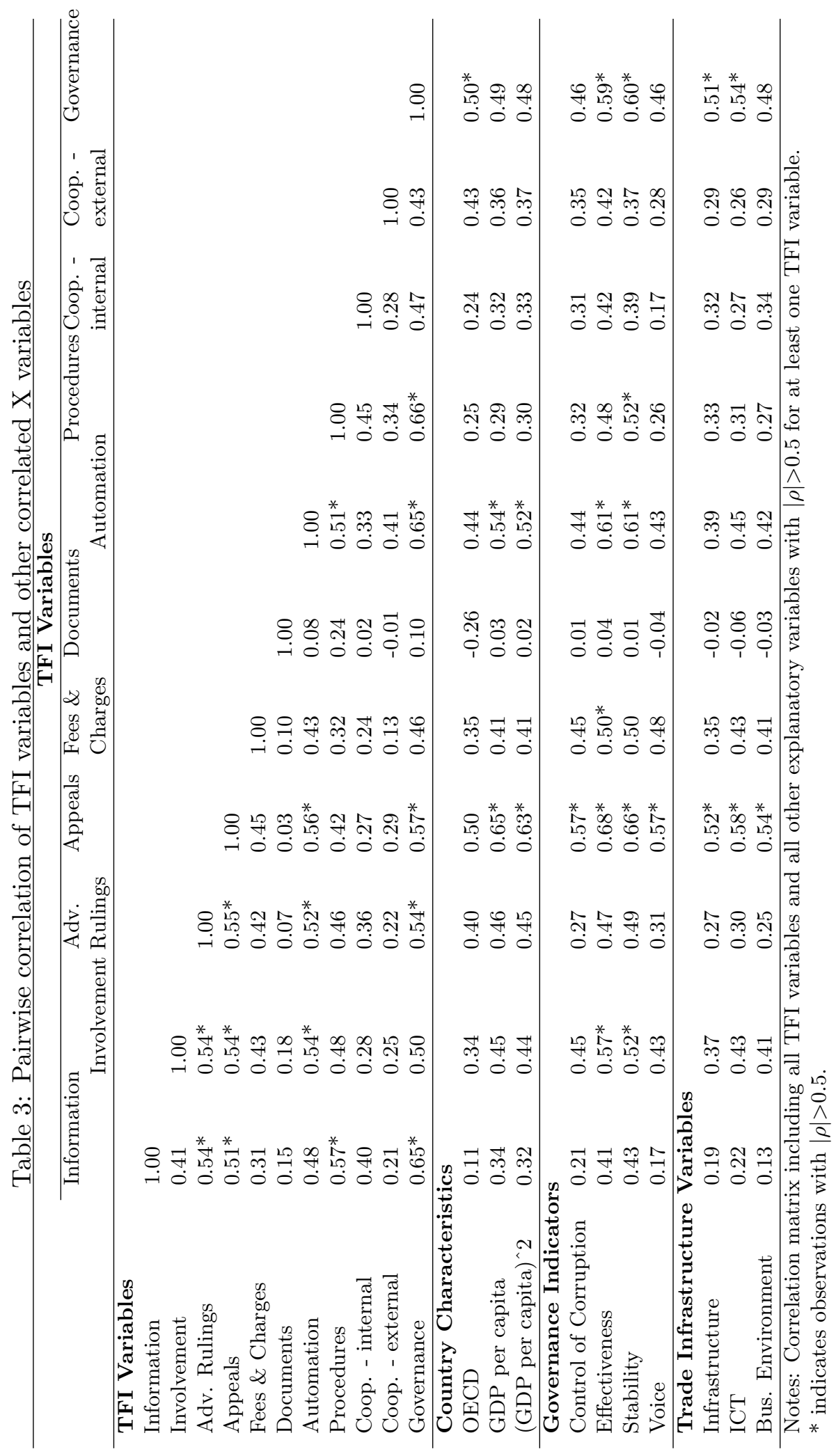


We begin our analysis by checking for multi-collinearity among the TFI policy variables themselves. The condition number for the matrix of TFI variables is 23.1, which suggests mild cause for concern about multi-collinearity, but not severe concern. The Belsley et al. (1980) procedure accommodates MI, and we use MI to bring in additional countries with incomplete data. Since the countries that are added through MI might have approaches to trade facilitation policy that differ from those with complete data, we might expect their inclusion in the analysis to reduce our measures of multicollinearity risk. We do indeed find smaller condition numbers using MI. Across 80 imputations of the policy data, the range of the condition numbers associated with the matrix of TFI data are 15.59 to 18.74 , which indicates that including the imputed policy data generates a small reduction in the already mild multicollinearity risk.

The analysis thus far has only considered the TFI policy data. We jointly consider the TFI data with other right hand side variables: the country characteristics, the governance indicators and the trade infrastructure variables. This produces five eigen vectors with condition numbers exceeding 30 and a maximum value of $182 .{ }^{27}$ These high condition number estimates over the complete set of variables are reduced somewhat when we include countries that require imputed data, but the lower figures (ranging from 127-141) still leave severe cause for concern. This evidence of multi-collinearity in our data motivates our subsequent application of the LASSO procedures.

\section{Estimating framework}

Our estimating framework takes into account two features of the data that are relevant for our exercise. First, the trade facilitation policy data that interest us are missing many observations. Second, our sample size is relatively small (183 countries), while there are a relatively large number $(40+)$ of $\mathrm{X}$ variables that might affect the outcomes of interest. Moreover, there is evidence of multicollinearity amongst the $\mathrm{X}$ variables, which makes standard OLS estimation inefficient. We design our estimating framework to address these issues jointly.

\footnotetext{
${ }^{27}$ The condition number test for collinearity includes a second necessary condition, which is also obtained in the full set of data. That second condition identifies two non-TFI variables that are significant risks for multicollinearity. The LASSO procedure we apply excludes both of these variables from the final estimates.
} 


\subsection{Multiple Imputation}

As noted above, one of the significant estimation challenges we face is the large amount of the TFI data that is missing. ${ }^{28}$ Data collection in an international setting is always challenging. In this case, where the goal of the collection effort was to provide detailed information on a topic that had not been widely studied, it is understandable that the TFI data are incomplete. The difficulty of the collection effort nonetheless leaves us with important estimation challenges.

A common response to missing data on the right hand side is simply to exclude it, thereby restricting inferences to the sample of observations with complete data. This process, known as listwise deletion, is only valid under the assumption that the missing data are missing completely at random (MCAR). The MCAR assumption is invalid in our sample, because the sub-sample of countries with complete policy data is not representative of the whole. ${ }^{29}$ Listwise deletion would also be problematic in our setting because many countries have some TFI policy data available, even while the data is missing for only one or two policy measures. In this context listwise deletion would lead us to discard useful data on cross-country policy variation in circumstances where the country lacks information on a single TFI variable. This would be especially problematic in our setting because the sample size is already rather small. In order to avoid discarding valuable data, we adopt well-developed methods for making inferences in the presence of missing data that are not MCAR.

Our strategy for dealing with the missing policy data is to employ multiple imputation (MI) methods first introduced by Rubin (1976). In broad terms, what MI does is to predict the missing policy data (i.e. impute it) in a manner that recognizes uncertainty about the values of the missing data, while at the same time maintaining the overall covariance structure of the right hand side variables. The procedure adopts multiple imputations so that causal inferences are not being driven by the randomness inherent in a given imputation. Standard errors are calculated so as to account for parameter uncertainty within an imputation and across imputations.

MI does not require that data be MCAR to be valid. Rather, the data must satisfy the sub-

\footnotetext{
${ }^{28}$ The trade infrastructure variables we employ also have missing data. Three countries (Federated States of Micronesia, San Marino, and Syrian Arab Republic) have missing openness data and we impute these in those specifications that include an openness variable.

${ }^{29}$ For example, in countries for which the TFI variable Information Availability is reported, the mean value of the $T A B$ total cost of importing is US $\$ 445$. For countries without data reported on the Information Availability the mean total cost of importing is US $\$ 587$. The difference between the two means is significantly different than 0 at a 5 percent level of significance. Similar disparities between countries with missing and non-missing data apply for the other TFI variables.
} 
stantially weaker missing at random (MAR) criterion. MAR is satisfied if the variables used in the prediction of the missing data adequately control for non-random sources of error in the missing data. While we are unable to formally test the MAR assumption, the wide variety of other data we employ in the process of imputation give us a high level of confidence that the errors in the imputation model are random and thus satisfy MAR. ${ }^{30}$ While we are not able to test the MAR assumption formally, we have applied alternate imputation methods and found the results to be stable across alternative treatments. ${ }^{31}$ These results offer further support to our assumption that the data are MAR.

Multiple imputation is a simulation-based statistical technique for handling missing data that consists of three steps: imputation, analysis and combination (Rubin, 1987). In the first step, missing data are imputed $M$ times to generate $M$ imputations (that is, $M$ completed data sets). Imputations are often based on a Bayesian model of the variables with missing values, given variables with observed data. For example, in our case we apply the predictive mean matching imputation method. This is a Bayesian method similar to imputation via a linear regression that regresses the variable with missing data on the variables without missing values, and use the coefficients to predict the missing values. ${ }^{32}$ Variability in the imputed data across imputations occurs because the predictive mean matching algorithm draws from the non-degenerate posterior distribution of the fitted missing data. The second step is to conduct the desired analysis on each imputation, separately, to obtain coefficient estimates of $\hat{\beta}_{m}$ for parameters of interest $\beta$ and estimates of $V_{m}$ for variance of $\hat{\beta}_{m}(m=1,2, \ldots, M) .{ }^{33}$ The third step combines results obtained from the completed second step into a single multiple-imputation result $\left(\hat{\beta}_{M I}, T\right)$. In this case the MI estimate is the average of the estimates on each imputation: $\hat{\beta}_{M I}=\sum_{m=1}^{M} \hat{\beta}_{m} / M$. The variance of $\left(\hat{\beta}_{M I}, T\right)$, has two components: the within imputation variability $\bar{V}=\sum_{m=1}^{M} V_{m} / M$, and the between imputation variability $B=\frac{1}{M-1} \sum_{m=1}^{M}\left(\hat{\beta}_{m}-\hat{\beta}_{M I}\right)^{2}$. The combined variance, $T$, is $T=\bar{V}+\frac{M+1}{M} B$.

Ideally the imputation model in the first step and the analysis model in the second step are the same Bayesian model. In our case we use the Bayesian predictive mean matching model in the first step, but our second-step analysis models are frequentist. The repeated-imputation inference is

\footnotetext{
${ }^{30}$ The prediction model used in imputation includes all of the $\mathrm{X}$ variables we consider in estimation (income, geography, governance, infrastructure, etc.), the available TFI data, and the outcome variable that is employed in each estimation model. In this context our extremely rich set of covariates substantially limits the possibility that the missing data are correlated with an unobservable.

${ }^{31}$ Specifically, our main results use the predictive mean matching model for imputation, but in sensitivity analysis we also used the truncated regression model.

${ }^{32}$ Predictive mean matching is preferable to linear regression because it does not impose normality.

${ }^{33}$ In our case, this means running the OLS model on each of the $M=80$ completed data sets.
} 
nonetheless statistically valid under some general conditions, including (1) the multiple imputations are proper and (2) complete data inference based on $\left(\hat{\beta}_{m}, V_{m}\right)$ is randomization valid. To ensure the multiple imputations are proper in the first step, the imputation model must include all predictors relevant to the missing data mechanism, and preserve all data characteristics that are explored in the analysis step. In our study, we include all variables used in the analysis model, i.e. not only independent variables of country characteristics but also dependent customs performance indicators. Complete data inference based on $\left(\hat{\beta}_{m}, V_{m}\right)$ is randomization valid, if $\hat{\beta}_{m} \backsim N\left(\beta, \operatorname{Var}\left(\hat{\beta}_{m}\right)\right)$ and $V_{m}$ is a consistent estimate of $\operatorname{Var}\left(\hat{\beta}_{m}\right)$, under the assumption of infinite sample. When the number of imputations is finite, for a scalar $Q$,

$$
\left(\hat{Q}_{M I}-Q\right) T^{-1 / 2} \backsim t_{\nu}
$$

where degrees of freedom $\nu=(M-1)\left(1+\frac{1}{M+1} \frac{\bar{U}}{B}\right)$ (Rubin and Schenker, 1986). ${ }^{34}$

We use the well-established Stata MI package to conduct the above procedures. ${ }^{35}$ Given the significant proportion of missing values for our 11 policy measures and 3 trade infrastructure variables, we choose $M=80$ in the first step so that we can obtain stable results (Kenward and Carpenter, 2007; Horton and Lipsitz, 2001). Summary statistics for the selected imputations shown in Table 4 look reasonable in that the summary statistics of the imputed data are quite stable across the first and last imputations, and are not overly different from those that are observed for the initial data set (in Table 1).

Table 4: Summary Statistics and Number of Observations for the 1st and 80th imputations

\begin{tabular}{|c|c|c|c|c|c|c|c|c|c|c|}
\hline \multirow[b]{2}{*}{ Variable } & \multicolumn{5}{|c|}{ the 1st imputation } & \multicolumn{5}{|c|}{ the 80th imputation } \\
\hline & $\begin{array}{l}\text { \# of } \\
\text { Obs }\end{array}$ & Mean & $\begin{array}{l}\text { Std. } \\
\text { Dev. }\end{array}$ & Min & $\operatorname{Max}$ & $\begin{array}{l}\text { \# of } \\
\text { Obs }\end{array}$ & Mean & $\begin{array}{l}\text { Std. } \\
\text { Dev. }\end{array}$ & Min & Max \\
\hline \multicolumn{11}{|c|}{ OECD trade facilitation indicators } \\
\hline Information & 183 & 1.35 & 0.51 & 0 & 2 & 183 & 1.35 & 0.51 & 0 & 2 \\
\hline Involvement & 183 & 1.18 & 0.54 & 0 & 2 & 183 & 1.16 & 0.54 & 0 & 2 \\
\hline Advance Rulings & 183 & 1.01 & 0.68 & 0 & 2 & 183 & 1.03 & 0.70 & 0 & 2 \\
\hline Appeal & 183 & 1.29 & 0.49 & 0 & 2 & 183 & 1.29 & 0.47 & 0 & 2 \\
\hline Fees \& charges & 183 & 1.21 & 0.47 & 0 & 2 & 183 & 1.19 & 0.47 & 0 & 2 \\
\hline Documents & 183 & 1.38 & 0.28 & 0.59 & 2 & 183 & 1.38 & 0.27 & 0.59 & 2 \\
\hline Automation & 183 & 1.13 & 0.57 & 0 & 2 & 183 & 1.15 & 0.54 & 0 & 2 \\
\hline Procedures & 183 & 1.09 & 0.34 & 0.22 & 1.87 & 183 & 1.06 & 0.36 & 0.22 & 1.87 \\
\hline Cooperation - internal & 183 & 1.17 & 0.61 & 0 & 2 & 183 & 1.19 & 0.60 & 0 & 2 \\
\hline Cooperation - external & 183 & 0.99 & 0.79 & 0 & 2 & 183 & 0.92 & 0.79 & 0 & 2 \\
\hline Governance & 183 & 1.11 & 0.65 & 0 & 2 & 183 & 1.12 & 0.63 & 0 & 2 \\
\hline \multicolumn{11}{|c|}{ Trade infrastructure variables } \\
\hline Phys. Infra. & 183 & 0.45 & 0.22 & 0.10 & 1 & 183 & 0.44 & 0.22 & 0.10 & 1 \\
\hline $\mathrm{ICT}$ & 183 & 0.48 & 0.22 & 0.12 & 1 & 183 & 0.51 & 0.22 & 0.12 & 1 \\
\hline Bus. Environment & 183 & 0.41 & 0.24 & 0.01 & 1 & 183 & 0.41 & 0.23 & 0.01 & 1 \\
\hline
\end{tabular}

\footnotetext{
${ }^{34}$ For detailed discussion, please refer to chapter of 3 and 4 of Rubin (1987).

${ }^{35}$ For technical details, refer to Stata (2013).
} 
One additional complication in our data is that the TFI variables themselves are averages of subindicators that are sometimes missing data. Moïsé and Sorescu (2013) explain that their standard for publishing an observation was that at least $40 \%$ of the available sub-indicators were available for use in the averaging across sub-indicators. The potential effects of this protocol on our estimation are somewhat difficult to determine. One possible consequence of the procedure would be that the reported TFI observations with relatively more missing sub-indicators have greater variability around their true mean because they are averaged over fewer sub-indicators. This should generate imputed data that have greater variability across imputations, which would inflate the standard errors of the MI estimates. Another possibility is that the missing subcomponents of given TFI variables are biased in one direction (for example, if the mean score on unreported subcomponents would have been below the mean for reported subcomponents), then the predictive mean matching algorithm we use to impute values for unreported data should introduce the same directional bias for the imputed observations as exists in the reported TFI data. Without access to the underlying survey data that formed the basis of the OECD scores we are unable to test these phenomena. ${ }^{36}$ Lacking access to the raw policy data that the OECD uses to compile the scores, we are left to take the TFI data as given. ${ }^{37}$

\subsection{Variable Selection}

Given the relatively large number of potential independent variables in this study and the multicollinearity among them, conventional OLS estimation may be inefficient. We adopt the least absolute shrinkage and selection operator (LASSO) of Tibshirani (1996) to conduct variable selection and to enhance prediction accuracy. ${ }^{38}$

Let $y_{i}$ denote a dependent variable of interest for the $i$ th $(i=1,2, \ldots, N)$ country, and $x_{m, i j}$ indicate the $j$ th $(j=1,2, \ldots, P)$ candidate covariate for the $i$ th country from the $m$ th imputed data set. ${ }^{39}$ Using our log-linear regression model as an example, for the $m$ th imputed data the regression

\footnotetext{
${ }^{36}$ Ideally, from the point of view of our estimation model, the OECD would themselves apply MI on the subcomponents that are missing. This would substantially reduce problems of inference, and may even be informative about the underlying policy situation.

${ }^{37}$ The literature using the TFI data that we review above also takes those data as given.

${ }^{38}$ The theoretical properties of LASSO method have been thoroughly studied in the literature, for example, Fan and Li (2001) and Knight and Fu (2000).

${ }^{39}$ All dependent variables of interest in this study are fully observed without missing values. The LPI data have fewer observations but we restrict our inferences to the available subsample rather than imputing a substantial amount of outcome data.
} 
model would appear as

$$
y_{i}=\beta_{m, 0}+\sum_{j=1}^{P} \beta_{m, j} x_{m, i j}+\varepsilon_{m, i}
$$

where $\beta_{m, j}$ 's are the regression coefficients for variables in the $m$ th imputed data set, and $\varepsilon_{m, i}$ is the random error term for the outcome variable in the $i$ th country for the $m$ th imputed data set.

Before turning to the group LASSO estimator we use to implement LASSO with multiple imputation, consider first a form of the LASSO method that would select variables for each imputed data set separately. For a single data set, variable selection using the LASSO method is achieved by penalizing the $l_{1}$ norm of the regression coefficients:

$$
\min _{\beta_{m, j}} \sum_{i=1}^{N}\left(y_{i}-\beta_{m, 0}-\sum_{j=1}^{P} \beta_{m, j} x_{m, i j}\right)^{2}+\lambda \sum_{j=1}^{P}\left|\beta_{m, j}\right|,
$$

where $\lambda$ is a non-negative tuning parameter that controls the penalty applied to larger values of $\left|\beta_{m, j}\right|{ }^{40}$ If the tuning parameter is 0, i.e. no penalty at all, LASSO estimation collapses to the conventional estimating model without variable selection. By contrast, if the tuning parameter is large enough, no variable will be selected (i.e. all coefficients are estimated as 0 ). We select the tuning parameter by minimizing a Bayesian Information Criterion (BIC) appropriate to the LASSO method, as described in (Zou and Hastie, 2005), and choose the value of $\lambda$ that minimizes BIC.

Were we to apply a LASSO procedure to each of the $M$ data sets, we would likely observe that the procedure selects different variables in different imputations. This would make it difficult to combine results from different data sets and to conduct inference. To solve this problem, we adopt the multiple imputation-least absolute shrinkage and selection operator (MI-LASSO) method proposed by Chen and Wang (2013). ${ }^{41}$

In order to obtain a consistent selection of variables across all imputed datasets, this MI-LASSO method fits models on all imputed datasets jointly by adapting the group LASSO penalty (Yuan and Lin, 2006; Huang et al., 2010) to estimation in an MI setting. Formally, we solve

$$
\min _{\beta_{m, j}} \sum_{m=1}^{M} \sum_{i=1}^{N}\left(y_{i}-\beta_{m, 0}-\sum_{j=1}^{P} \beta_{m, j} x_{m, i j}\right)^{2}+\lambda \sum_{j=1}^{P} \sqrt{\sum_{m=1}^{M} \beta_{m, j}^{2}},
$$

\footnotetext{
${ }^{40}$ This addresses multi-collinearity because, for example, two highly collinear X variables might have large $\beta_{m, j}$ 's of opposite signs.

${ }^{41}$ This estimator was developed for applications in the field of medicine. As far as we are aware ours is the first application of this estimator in the international trade literature, and possibly in the field of Economics more generally.
} 
where $\sum_{j=1}^{P} \sqrt{\sum_{m=1}^{M} \beta_{m, j}^{2}}$ is the group LASSO penalty proposed by Yuan and Lin (2006). ${ }^{42}$ The group LASSO penalty applies to all coefficient estimates associated with a particular covariate across all the imputed datasets. This form of the group LASSO penalty insures that the estimated coefficients for each covariate are either all exactly zero or all non-zero; thereby guaranteeing the consistency of variable selection over all imputed datasets. For detailed discussion of the MI-LASSO procedure, please refer to Chen and Wang (2013).

\subsection{Post-LASSO estimation}

The group LASSO approach to incorporating MI produces only point estimates of the coefficients on selected variables, not standard errors. In order to produce standard errors we conduct a further estimation procedure that includes only the selected right hand side variables in a simple specification without the LASSO penalty. In the post-LASSO estimation we apply the OLS or Poisson objective function, as appropriate, and again apply the MI methods described above. One benefit of this approach is that the OLS estimates once again provide an estimate of $R^{2}$, which can be compared against the $R^{2}$ from the full OLS specifications in Appendix Tables A3-A5 to determine the amount of lost information from the variable selection procedure. One complication of conducting post-Lasso estimation is that it generates different estimates of $\beta_{m, j}$, because the coefficients no longer face the LASSO penalty. We report the results of post-LASSO estimates for the variables that were selected by the MI-LASSO procedure described above.

\section{Results}

In this section we report empirical results from the estimation models, as well as some counterfactual calculations. All of the reported estimates rely on multiple imputation to incorporate missing data. We begin with OLS estimates, which provide a transparent guide to the relative importance of TFI and non-TFI variables in explaining the variation in the outcome variables. One way that we demonstrate relative importance is to conduct F-tests for exclusion of groups of independent variables. We then turn to the estimates produced by the MI-LASSO procedure. We check these

${ }^{42}$ To select the tuning parameter for MI-LASSO, we calculate the BIC as

$$
\mathrm{BIC}=\log \left(\frac{1}{N M} \sum_{m=1}^{M} \sum_{i=1}^{N}\left(y_{i}-\hat{\beta}_{m, 0}-\sum_{j=1}^{P} \hat{\beta}_{m, j} x_{m, i j}\right)^{2}\right)+d f_{2} \cdot \frac{\log (N M)}{N M},
$$

where $d f_{2}$ is the degree of freedom and can be estimated by the method proposed by Yuan and Lin (2006). 
results with a Poisson specification of the MI-LASSO procedure. In each case we report the results of post-LASSO estimates with standard errors. Finally we report the results of counterfactual analysis that calculates the effects of changing the only trade facilitation policy variable with a robust link to an outcome, the TFI variable, procedures.

\subsection{OLS results}

Before turning to the LASSO estimation we begin with log-linear OLS regression analysis with MI. ${ }^{43}$ The purpose of this analysis is to provide a transparent guide to respective contributions of various classes of right hand side variables for explaining the outcome variables of interest. For each of the six outcome variables we study, we estimate regressions on the TFI policy data alone, on the non-policy data, and finally on the entire set of independent variables. The $R^{2}$ and adjusted $R^{2}$ estimates from these regressions provide a guide to the share of variation in the outcome variable that is explained by policy data, as well as the marginal impact of the policy variables on explained variation. OLS regressions are also useful because they offer a well-understood test of joint exclusion that can be applied to blocks of variables. For each outcome variable we apply F-tests to the TFI variables as well as other blocks of variables included in the regression.

We report complete OLS regression results in appendix Tables A3-A5. We do not dwell on individual coefficient estimates at this stage, but rather focus on broad characteristics of the regression that inform an understanding of relative importance of groups of independent variables for each outcome variable. These broad characteristics we reproduce in Table 5. The regressions on the TFI data alone reveal a much tighter unconditional link between the LPI data and the TFI data than exists between the TAB and TFI data. The Adjusted $R^{2}$ measures suggest that policy variation explains roughly half of the variation in LPI data, but only 15-30 percent of the variation in the TAB data. ${ }^{44}$ This may reflect a tighter link between underlying trade facilitation policies and the LPI measures, which were designed with a particular focus on trade logistics. The TAB data cover a much broader set of activities (most notably transport), and so might have weaker unconditional links to policy variation.

Of course, for purposes of policy analysis, one wants to understand the conditional impact of policy, not the unconditional impact. The underlying policy variation that exists in the cross-

\footnotetext{
${ }^{43}$ The TAB data contain zero observations (in the case of customs unions). In order to retain these outcome data in the OLS regressions we replace 0 with one-tenth of the minimum of the strictly positive values prior to logging them.

${ }^{44}$ The TAB import variables are more tightly linked to policy variation than are the export outcomes.
} 
section is likely to be endogenous to larger forces, including countries' geography and their levels of development. As our correlation matrix shows, some of the TFI variables are highly correlated with broader measures of governance. The question of policy interest is the degree to which changes in policy alone, holding fixed other country characteristics, would affect the outcome variables used for monitoring. If other forces are driving variation in the measured performance then there is less scope for policy change to affect the outcomes of interest.

With this point in mind we consider variation across outcome variables in the Adjusted $R^{2}$ statistics for non-policy variables, including controls for principal export and import partner and principal export product. ${ }^{45}$ It is clear that the non-policy variables do a better job of explaining all the outcome variables than do the TFI policy data alone. Adjusted $R^{2}$ estimates range from 0.6 to 0.8 when only control variables are included.

More interesting is the marginal effect on the explained variation that occurs with the move from the regressions without policy data to the regressions with a complete right hand side. We see that the effect of including the policy data on the explained variation is quite small. After the adjustment to $R^{2}$ to account for the additional variables we find that the policy variables add almost no explanatory power to the regressions. ${ }^{46}$ In broad terms it seems that that the information that is contained in the TFI policy data replicates information already contained in country characteristics. One plausible explanation is that TFI policies themselves are broadly determined by the other variables that we study. An alternative is that the vector of control variables is sufficiently large that the regressions are unable to separately identify the effects of individual policies.

In order to formalize this in a more rigorous fashion, as well as to consider the contributions of subsets of the non-policy variables, we report the results of F-tests of exclusion for the TFI variables and each of the subsets of variables included in the regression analysis. These results are reported in the bottom half of Table 5. For each group of variables we report results of an F-test of the hypothesis that all coefficients on the relevant variables equal zero.

The results of the F-tests on the non-policy variables are informative. The broad country characteristics that are included to control for variation in national geographies, economic characteristics and openness to trade clearly matter, collectively, for the outcome variables we study. The asso-

\footnotetext{
${ }^{45}$ These latter variables are included primarily because they affect the hypothetical shipment considered by the $T A B$ surveys. We include them in the LPI regressions as well, lest they affect respondents implicitly. Since the LPI data do not imply a direction of the shipment we include both import and export control variables.

${ }^{46}$ One could draw similar inferences looking at the raw $R^{2}$ statistics in appendix tables A3-A5. Those statistics reveal very small increases in raw $R^{2}$ coming from the inclusion of policy data.
} 
ciated F-tests have very low p-values across all specifications. ${ }^{47}$ The other set of variables that is critical for understanding the $T A B$ data are the import and export partner characteristics, with p-values approaching zero. The TAB survey names a specific trading partner country in its description of the hypothetical shipment, and countries whose largest trading partner shares a land border and/or a PTA/customs union have very different $T A B$ outcomes than countries whose largest trading partners do not share those characteristics. On the other hand, these principal trading partner characteristics do not matter for the LPI outcomes, which probably reflects the fact that the identity of the country's largest trading partner is not salient for the LPI survey. The set of variables that do matter collectively for the LPI data are the Worldwide Governance Indicators. This too is plausible because respondents may well consider general measures of governance when reporting on logistics performance. What is interesting here is that the governance indicators matter, even when trade facilitation policy measures themselves are included in the specification.

While the F-tests of subsets of control variables show that some subsets of variables are critical for explaining variation in the outcome variables, joint exclusion tests of the TFI variables reveal no statistically significant joint effect of the policy variables on any of the outcome variables we study. This is consistent with the finding that including the TFI variables adds little if anything to $R^{2}$. We turn to the MI-LASSO procedures to check the robustness of this insight with an estimator designed specifically to address multi-collinearity.

\footnotetext{
${ }^{47}$ We also conduct this analysis excluding the openness variable and estimating on samples that exclude large outliers among the TAB data. In addition, we estimate with the LPI data in levels rather than logs. The same blocks of variables are significant and insignificant in these exercises.
} 


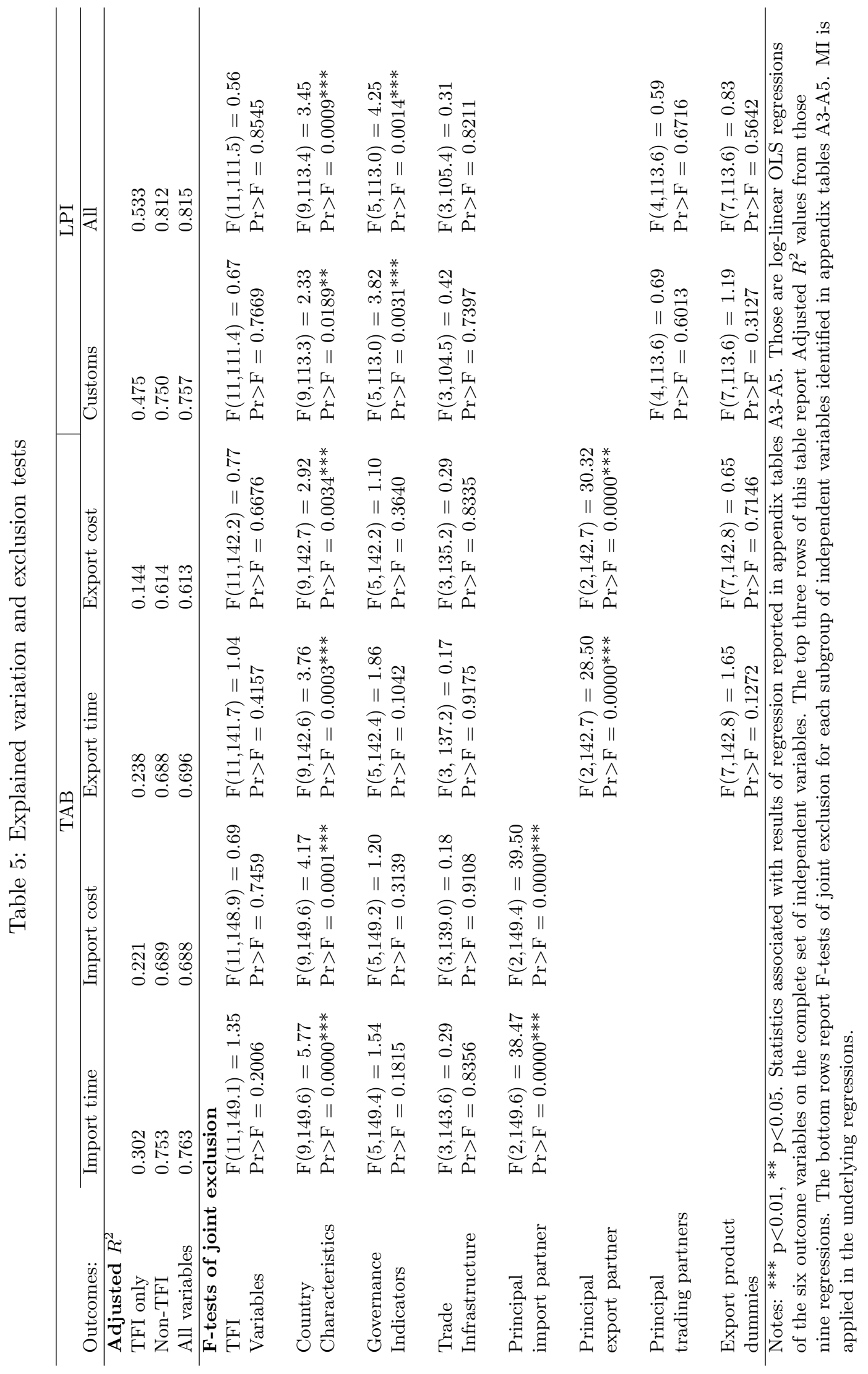




\subsection{MI-LASSO estimates}

We conduct MI-LASSO and post-LASSO estimation for all six outcome variables using two specifications: a log-linear OLS specification and a Poisson specification in levels. The OLS specification allows a transparent comparison of results from the earlier OLS regressions. The Poisson estimates offer an alternative specification that allows zero observations to enter the estimation without adjustment. The Poisson specification also offers an indirect check on the possible importance of heteroskedastic errors.

The OLS results are reported in Table 6, while the Poisson results appear in Table 7. Both sets of estimates offer broadly similar lessons about the determinants of the indicators. In the case of the TAB data, the country characteristics and the trading partner dummies contain the most influential variables, while the LPI outcomes are explained by country characteristics and governance indicators. These are consistent with the F-tests we conducted on the full specification of the OLS model with a complete set of variables.

Before turning to the coefficient estimates, we first note that the $R^{2}$ values in Table 6 are only slightly smaller than those reported in Appendix Tables A3-A5. Those specifications include the complete set of control variables, and the LASSO results are comparatively sparse. This implies that the excluded variables were not at all influential in explaining the variation in the outcome variables.

We begin our consideration of the coefficient estimates by checking those on the non-policy variables. Amongst those variables, the vast majority of coefficient estimates take the expected sign. This is even more the case if we focus on coefficients that are statistically different than zero. ${ }^{48}$ The results indicate that countries that share land borders with their largest trading partners see much lower TAB reported values of time and cost. Landlocked countries have larger reported total import times, while countries with larger land areas have consistently higher TAB-reported values of total export time and cost. OECD membership predicts better TAB outcomes in all of the OLS specifications, but only significantly so for import cost in the Poisson specification. Among the governance variables, the LASSO procedure identifies effectiveness and regulatory quality as the specific indicators that help to predict logged LPI scores. A less intuitive result is that the GDP

\footnotetext{
${ }^{48}$ Among these coefficients, only the positive coefficient on GDP in the Poisson specification for TAB import times takes an unexpected sign. The relationship between economy size and import time is not one for which strong priors seem warranted.
} 
variable also matters for both LPI indexes we study. ${ }^{49}$

Turning to the TFI variables, we see that the MI-LASSO procedure identified many more variables as influential for TAB import time than for the other outcome variables we study. The coefficients on most of these are, however, insignificant in post-LASSO estimation. Countries with better procedures have substantially lower reported import times across both OLS and Poisson specifications. Both estimated coefficients are large, suggesting large effects of simplified procedures on import times. There is one TFI coefficient in each specification of import time that takes an unexpected sign and is statistically significant. The larger number of TFI variables selected by the LASSO procedure for TAB import times leaves room for the TFI variables to have offsetting effects. For outcome variables other than TAB import time, fewer variables are selected by the LASSO procedure, and the coefficients on those variables generally take the expected sign.

In broad terms we take the lessons of MI-LASSO exercise to be that earlier inferences from the Ftests are generally robust. Country characteristics such as geography are important determinants of trade logistics outcomes. Our earlier lesson that governance variables matter for the LPI is now more nuanced, as the MI-LASSO procedure identified government effectiveness and regulatory quality as particularly relevant for LPI outcomes. Characteristics of a country's largest trading partner (which is identified in the TAB surveys) are also important for explaining TAB outcomes. The influence of these other variables leave little room for policy variation to matter for trade logistics outcomes. The only consistent exception appears to be our robust finding that countries with simpler trade procedures have lower TAB-reported import times.

\subsection{Other exercises}

We conduct a number of other exercises. For the most part these are robustness checks, but we also studied other outcomes for which we do not report tabular results. In this section we summarize that work.

The index nature of the LPI means that the choice of units is not obvious. For our main OLS specification we logged the LPI scores, but one might argue that they should enter the OLS regression in levels. We estimated an OLS specification of the LPI variables in levels and found results that were largely consistent with those reported in Table 6. The exceptions were that in the levels regression

\footnotetext{
${ }^{49}$ One issue that may be relevant for understanding the relatively small number of LASSO-selected variables in the LPI data is the relatively small number of observations reported for the LPI. The LPI appears to rotate some countries in and out of their reports. This implies fewer data points for a cross-sectional analysis like ours.
} 
the coefficient on the OECD dummy becomes significant at the 10 percent level for both the LPI variables, while the coefficient on the Effectiveness variable becomes insignificant for the customs subcomponent of LPI.

We have include lagged (and logged) openness in our primary specification, but one might argue that openness is endogenous to trade facilitation policies and it should therefore be excluded. We reestimated all the OLS models without including openness. Occasionally excluding openness meant that an additional variable was selected by the MI-LASSO procedure but found to be insignificant in post-LASSO estimation, and occasionally a coefficient that was not statistically significant became so. But in general the results were remarkably robust to excluding openness.

The TAB data are generally right-skewed, with a few outlier countries like Venezuela lying in the far right tail. In order to check for inordinate influence of these variables we trimmed the estimating sample by dropping observations with outcome data that were three or more standard deviations from the mean. This did not affect the LPI data, but meant that as many as five TAB observations were trimmed from an individual regression sample. While this led to minor changes in variable selection, or in the significance levels of selected variables, the results reported in the Tables 6 and 7 are consistent with the results of that exercise.

Our approach has been to study the most inclusive measures of time and cost reported in the TAB, but there are other outcome variables available to us. Among several other possibilities, we chose to study time and cost at the port or border as alternatives. Our reason for choosing this TAB subcomponent is that, unlike the other subcomponents, it measures phenomena that only occur after the shipment has begun to move. The effects of trade facilitation policies on moving goods seem the most salient, especially with respect to time outcomes. The general lesson from these exercises was that the trading partner characteristics were even more important for time and cost at the port or border than they are for the more inclusive measures. As a result, fewer variables were selected by the MI-LASSO procedure and fewer found to be statistically significant in post-LASSO estimation. The procedures variable that was identified as strongly significant for total import time was selected by the MI-LASSO procedure for time at the port or border, and a large but not statistically significant coefficient of the same sign in post-LASSO estimation. ${ }^{50}$

\footnotetext{
${ }^{50}$ In overland trade, traders often deal with some trade procedures at the border and others at an inland clearing point. In that sense the inclusive measure is probably preferable for inference.
} 
Table 6: MI-LASSO, OLS

\begin{tabular}{|c|c|c|c|c|c|c|}
\hline Variables & $\begin{array}{c}\text { Import Time } \\
\text { (1) }\end{array}$ & $\begin{array}{c}\text { Import Cost } \\
(2)\end{array}$ & $\begin{array}{c}\text { Export Time } \\
\text { (3) }\end{array}$ & $\begin{array}{l}\text { Export Cost } \\
\text { (4) }\end{array}$ & $\begin{array}{c}\text { LPI (Customs) } \\
(5)\end{array}$ & $\begin{array}{l}\text { LPI (All) } \\
(6)\end{array}$ \\
\hline Information & - & - & - & - & - & - \\
\hline Involvement & - & - & - & $\begin{array}{l}-0.158 \\
(0.206)\end{array}$ & - & - \\
\hline Advance Rulings & $\begin{array}{l}-0.044 \\
(0.220)\end{array}$ & $\begin{array}{l}-0.247^{*} \\
(0.146)\end{array}$ & - & - & - & - \\
\hline Appeal & - & $\begin{array}{l}-0.096 \\
(0.248)\end{array}$ & - & $\begin{array}{c}0.071 \\
(0.276)\end{array}$ & - & - \\
\hline Fees \& Charges & $\begin{array}{l}-0.281 \\
(0.288)\end{array}$ & - & - & $\begin{array}{l}-0.121 \\
(0.218)\end{array}$ & - & - \\
\hline Documents & - & - & - & - & - & - \\
\hline Automation & - & - & - & $\begin{array}{l}-0.005 \\
(0.214)\end{array}$ & - & - \\
\hline Procedures & $\begin{array}{c}-0.990^{* *} \\
(0.414)\end{array}$ & - & $\begin{array}{l}-0.252 \\
(0.362)\end{array}$ & $\begin{array}{l}-0.260 \\
(0.308)\end{array}$ & $\begin{array}{c}0.037 \\
(0.039)\end{array}$ & - \\
\hline Cooperation - internal & $\begin{array}{c}0.460^{* *} \\
(0.217)\end{array}$ & - & - & - & - & - \\
\hline Cooperation - external & - & - & - & - & - & - \\
\hline Governance & - & - & - & - & - & - \\
\hline Openness & $\begin{array}{c}-0.768^{* * *} \\
(0.287)\end{array}$ & $\begin{array}{c}-0.605^{* * *} \\
(0.177)\end{array}$ & $\begin{array}{l}-0.329 \\
(0.291)\end{array}$ & $\begin{array}{l}-0.045 \\
(0.220)\end{array}$ & - & - \\
\hline GDP per capita & $\begin{array}{l}-0.131 \\
(0.125)\end{array}$ & $\begin{array}{l}-0.054 \\
(0.084)\end{array}$ & $\begin{array}{l}-0.605 \\
(0.887)\end{array}$ & $\begin{array}{l}-0.624 \\
(0.732)\end{array}$ & - & - \\
\hline$(\text { GDP per capita })^{\wedge} 2$ & - & - & $\begin{array}{c}0.032 \\
(0.053)\end{array}$ & $\begin{array}{c}0.037 \\
(0.043)\end{array}$ & - & - \\
\hline GDP & - & - & - & - & $\begin{array}{c}0.016^{* *} \\
(0.007)\end{array}$ & $\begin{array}{c}0.028^{* * *} \\
(0.005)\end{array}$ \\
\hline Landlocked & $\begin{array}{c}1.166^{* * *} \\
(0.382)\end{array}$ & - & - & - & - & - \\
\hline Island & $\begin{array}{l}0.761^{* *} \\
(0.364)\end{array}$ & - & - & $\begin{array}{c}0.682^{* *} \\
(0.269)\end{array}$ & - & - \\
\hline WTO & - & - & - & - & - & - \\
\hline OECD & $\begin{array}{c}-2.481^{* * *} \\
(0.428)\end{array}$ & $\begin{array}{c}-1.104^{* * *} \\
(0.289)\end{array}$ & $\begin{array}{c}-1.993^{* * *} \\
(0.478)\end{array}$ & $\begin{array}{c}-1.127 * * * \\
(0.371)\end{array}$ & $\begin{array}{c}0.042 \\
(0.035)\end{array}$ & $\begin{array}{c}0.000 \\
(0.029)\end{array}$ \\
\hline Land Area & $\begin{array}{c}0.128^{* *} \\
(0.065)\end{array}$ & - & $\begin{array}{c}0.193^{* * *} \\
(0.057)\end{array}$ & $\begin{array}{c}0.203^{* * *} \\
(0.051)\end{array}$ & - & - \\
\hline Control of Corruption & - & - & - & - & $\begin{array}{c}0.029 \\
(0.029)\end{array}$ & - \\
\hline Effectiveness & - & - & - & - & $\begin{array}{c}0.050 \\
(0.040)\end{array}$ & $\begin{array}{c}0.065^{* *} \\
(0.026)\end{array}$ \\
\hline Stability & $\begin{array}{c}-0.434^{* *} \\
(0.195)\end{array}$ & $\begin{array}{c}-0.190 \\
(0.132)\end{array}$ & $\begin{array}{c}-0.172 \\
(0.188)\end{array}$ & - & - & - \\
\hline Reg quality & $\begin{array}{c}0.109 \\
(0.252)\end{array}$ & $\begin{array}{c}0.049 \\
(0.155)\end{array}$ & - & - & $\begin{array}{l}0.057^{*} \\
(0.030)\end{array}$ & $\begin{array}{l}0.049^{* *} \\
(0.025)\end{array}$ \\
\hline Voice & $\begin{array}{l}-0.205 \\
(0.201) \\
\end{array}$ & $\begin{array}{l}-0.064 \\
(0.126) \\
\end{array}$ & $\begin{array}{l}-0.099 \\
(0.184) \\
\end{array}$ & $\begin{array}{l}-0.156 \\
(0.134) \\
\end{array}$ & - & $\begin{array}{c}0.008 \\
(0.015) \\
\end{array}$ \\
\hline Infrastructure & - & - & - & - & $\begin{array}{c}0.022 \\
(0.100)\end{array}$ & $\begin{array}{c}0.041 \\
(0.080)\end{array}$ \\
\hline $\mathrm{ICT}$ & - & - & - & - & $\begin{array}{c}0.105 \\
(0.107)\end{array}$ & - \\
\hline Bus. Environment & - & - & - & - & - & - \\
\hline \multicolumn{7}{|l|}{ Import Partner } \\
\hline Land Border & $\begin{array}{c}-2.981 * * * \\
(0.357)\end{array}$ & $\begin{array}{c}-1.735 * * * \\
(0.178)\end{array}$ & & & - & - \\
\hline PTA or CU & $\begin{array}{c}-0.604^{* *} \\
(0.253) \\
\end{array}$ & $\begin{array}{c}-0.401^{* *} \\
(0.175) \\
\end{array}$ & & & - & - \\
\hline \multicolumn{7}{|l|}{ Export Partner } \\
\hline Land Border & & & $\begin{array}{c}-2.063^{* * *} \\
(0.256)\end{array}$ & $\begin{array}{c}-1.786^{* * *} \\
(0.206)\end{array}$ & - & - \\
\hline PTA or CU & & & $\begin{array}{c}-0.694^{* * *} \\
(0.239)\end{array}$ & $\begin{array}{c}-0.273 \\
(0.184)\end{array}$ & - & - \\
\hline \multicolumn{3}{|c|}{ Animal, vegetable or food } & $\begin{array}{c}0.344 \\
(0.276)\end{array}$ & $\begin{array}{c}0.236 \\
(0.216)\end{array}$ & - & - \\
\hline \multicolumn{3}{|c|}{ Chemicals, plastics and rubbers } & - & - & - & - \\
\hline \multicolumn{3}{|c|}{ Hides, skins, textiles and footwear } & - & - & - & - \\
\hline \multicolumn{3}{|l|}{ Wood products } & - & - & - & \\
\hline \multicolumn{3}{|l|}{ Metals } & - & - & $\begin{array}{c}-0.076^{* * *} \\
(0.028)\end{array}$ & - \\
\hline \multicolumn{3}{|l|}{ Machinery and electrical } & $\begin{array}{c}-1.024^{* * *} \\
(0.338)\end{array}$ & $\begin{array}{l}-0.280 \\
(0.265)\end{array}$ & - & - \\
\hline \multicolumn{2}{|l|}{ Transport } & & $\begin{array}{c}-1.721^{* * *} \\
(0.577) \\
\end{array}$ & $\begin{array}{c}-0.621 \\
(0.448)\end{array}$ & - & - \\
\hline Constant & $\begin{array}{c}8.441^{* * *} \\
(2.160)\end{array}$ & $\begin{array}{c}10.054^{* * *} \\
(1.019)\end{array}$ & $\begin{array}{l}6.911^{*} \\
(4.137)\end{array}$ & $\begin{array}{l}7.107^{* *} \\
(3.405)\end{array}$ & $\begin{array}{c}0.696^{* * *} \\
(0.080)\end{array}$ & $\begin{array}{c}1.659^{* * *} \\
(0.162)\end{array}$ \\
\hline R-square & 0.781 & 0.683 & 0.706 & 0.652 & 0.753 & 0.813 \\
\hline Adj R-square & 0.761 & 0.665 & 0.683 & 0.616 & 0.737 & 0.803 \\
\hline Observations & 183 & 183 & 183 & 183 & 156 & 156 \\
\hline
\end{tabular}

Post-Lasso estimates. - indicates variable was excluded by the MI-LASSO procedure.

Note: Standard errors reported in parentheses. ${ }^{* *}$ indicates $1 \%$ significant, $* * 5 \%$ significant and $* 10 \%$ significant. 
Table 7: MI-LASSO, Poisson

\begin{tabular}{|c|c|c|c|c|c|c|}
\hline Variables & $\begin{array}{c}\text { Import Time } \\
\text { (1) }\end{array}$ & $\begin{array}{c}\text { Import Cost } \\
(2)\end{array}$ & $\begin{array}{c}\text { Export Time } \\
(3)\end{array}$ & $\begin{array}{c}\text { Export Cost } \\
(4)\end{array}$ & $\begin{array}{c}\text { LPI (Customs) } \\
(5)\end{array}$ & $\begin{array}{l}\text { LPI (All) } \\
(6)\end{array}$ \\
\hline Information & $\begin{array}{c}0.206 \\
(0.209)\end{array}$ & - & - & - & - & - \\
\hline Involvement & $\begin{array}{l}-0.207 \\
(0.149)\end{array}$ & - & $\begin{array}{l}-0.125 \\
(0.150)\end{array}$ & $\begin{array}{l}-0.173^{*} \\
(0.103)\end{array}$ & - & - \\
\hline Advance Rulings & - & $\begin{array}{l}-0.116 \\
(0.074)\end{array}$ & - & - & - & - \\
\hline Appeal & - & - & - & - & - & - \\
\hline Fees \& Charges & $\begin{array}{l}-0.174 \\
(0.184)\end{array}$ & - & - & - & - & - \\
\hline Documents & $\begin{array}{c}0.213 \\
(0.281)\end{array}$ & - & - & - & - & - \\
\hline Automation & $\begin{array}{l}0.305^{*} \\
(0.179)\end{array}$ & - & - & - & - & - \\
\hline Procedures & $\begin{array}{c}-0.721^{* *} \\
(0.282)\end{array}$ & - & $\begin{array}{l}-0.334 \\
(0.242)\end{array}$ & - & $\begin{array}{c}0.037 \\
(0.034)\end{array}$ & - \\
\hline Cooperation - internal & $\begin{array}{c}0.172 \\
(0.135)\end{array}$ & - & - & - & - & - \\
\hline Cooperation - external & $\begin{array}{c}0.081 \\
(0.105)\end{array}$ & - & - & - & - & - \\
\hline Governance & - & - & - & - & - & - \\
\hline Openness & $\begin{array}{l}-0.073 \\
(0.201)\end{array}$ & $\begin{array}{c}-0.386^{* * *} \\
(0.109)\end{array}$ & $\begin{array}{l}-0.071 \\
(0.159)\end{array}$ & - & - & - \\
\hline GDP per capita & $\begin{array}{c}-0.204^{* *} \\
(0.084)\end{array}$ & - & - & - & - & - \\
\hline$(\text { GDP per capita })^{\wedge} 2$ & - & - & - & - & - & - \\
\hline GDP & $\begin{array}{c}0.141 * * \\
(0.061)\end{array}$ & - & - & - & $\begin{array}{c}0.015^{* *} \\
(0.006)\end{array}$ & $\begin{array}{c}0.029 * * * \\
(0.005)\end{array}$ \\
\hline Landlocked & $\begin{array}{c}0.856^{* *} \\
(0.339)\end{array}$ & - & - & - & - & - \\
\hline Island & $\begin{array}{l}-0.091 \\
(0.176)\end{array}$ & - & - & - & - & - \\
\hline WTO & - & - & - & - & - & - \\
\hline OECD & $\begin{array}{l}-0.569 \\
(0.367)\end{array}$ & $\begin{array}{c}-0.593^{* * *} \\
(0.199)\end{array}$ & - & - & $\begin{array}{c}0.041 \\
(0.026)\end{array}$ & $\begin{array}{c}0.002 \\
(0.021)\end{array}$ \\
\hline Land Area & - & - & $\begin{array}{c}0.067^{* *} \\
(0.031)\end{array}$ & $\begin{array}{c}0.068^{* * *} \\
(0.020) \\
\end{array}$ & - & - \\
\hline Control of Corruption & - & - & $\begin{array}{l}-0.040 \\
(0.163)\end{array}$ & - & - & - \\
\hline Effectiveness & - & - & $\begin{array}{l}-0.006 \\
(0.203)\end{array}$ & $\begin{array}{l}-0.031 \\
(0.122)\end{array}$ & $\begin{array}{c}0.071^{* * *} \\
(0.026)\end{array}$ & $\begin{array}{c}0.064^{* * *} \\
(0.023)\end{array}$ \\
\hline Stability & $\begin{array}{l}-0.017 \\
(0.123)\end{array}$ & $\begin{array}{l}-0.101 \\
(0.073)\end{array}$ & - & - & - & - \\
\hline Reg quality & $\begin{array}{c}-0.602^{* * *} \\
(0.161)\end{array}$ & $\begin{array}{l}-0.087 \\
(0.071)\end{array}$ & $\begin{array}{c}-0.448^{* *} \\
(0.198)\end{array}$ & $\begin{array}{l}-0.189 \\
(0.135)\end{array}$ & $\begin{array}{c}0.056^{* *} \\
(0.025)\end{array}$ & $\begin{array}{c}0.053^{* * *} \\
(0.019)\end{array}$ \\
\hline Voice & - & - & $\begin{array}{l}-0.063 \\
(0.093) \\
\end{array}$ & $\begin{array}{l}-0.006 \\
(0.065) \\
\end{array}$ & - & - \\
\hline Infrastructure & $\begin{array}{l}-0.294 \\
(0.819)\end{array}$ & - & - & - & $\begin{array}{c}0.061 \\
(0.077)\end{array}$ & $\begin{array}{c}0.048 \\
(0.063)\end{array}$ \\
\hline $\mathrm{ICT}$ & $\begin{array}{c}0.821 \\
(0.831)\end{array}$ & - & - & - & $\begin{array}{c}0.103 \\
(0.084)\end{array}$ & $\begin{array}{c}0.110 \\
(0.069)\end{array}$ \\
\hline Bus. Environment & - & - & - & - & - & - \\
\hline \multicolumn{7}{|l|}{ Import Partner } \\
\hline Land Border & $\begin{array}{c}-1.610^{* * *} \\
(0.332)\end{array}$ & $\begin{array}{c}-0.973^{* * *} \\
(0.106)\end{array}$ & & & - & - \\
\hline PTA or CU & $\begin{array}{c}-0.573^{* * *} \\
(0.147)\end{array}$ & $\begin{array}{c}-0.300^{* * *} \\
(0.089)\end{array}$ & & & - & - \\
\hline \multicolumn{7}{|l|}{ Export Partner } \\
\hline Land Border & & & $\begin{array}{c}-0.870^{* * *} \\
(0.146)\end{array}$ & $\begin{array}{c}-1.254^{* * *} \\
(0.123)\end{array}$ & - & - \\
\hline PTA or CU & & & $\begin{array}{r}-0.264^{*} \\
(0.137)\end{array}$ & $\begin{array}{c}-0.170^{*} \\
(0.093)\end{array}$ & - & - \\
\hline Animal, vegetable or food & & & $\begin{array}{l}0.235^{*} \\
(0.133)\end{array}$ & - & - & - \\
\hline Chem, Plast, Rubber & & & - & - & - & - \\
\hline $\begin{array}{l}\text { Hides, skins, } \\
\text { textiles\& footwr }\end{array}$ & & & - & - & - & - \\
\hline Wood Products & & & - & - & - & - \\
\hline Metals & & & $\begin{array}{c}0.754^{* * * *} \\
(0.207)\end{array}$ & - & $\begin{array}{c}-0.069^{* * *} \\
(0.027)\end{array}$ & - \\
\hline Mach. \& Elec & & & - & - & - & - \\
\hline Transport & & & - & - & - & $\begin{array}{c}0.054^{* *} \\
(0.024)\end{array}$ \\
\hline Constant & $\begin{array}{c}5.071^{* * *} \\
(1.124) \\
\end{array}$ & $\begin{array}{c}8.362^{* * *} \\
(0.506)\end{array}$ & $\begin{array}{c}.095^{* * *} \\
(1.042) \\
\end{array}$ & $\begin{array}{c}5.711^{* * *} \\
(0.225)\end{array}$ & $\begin{array}{c}0.698^{* * *} \\
(0.071)\end{array}$ & $\begin{array}{c}0.651^{* * *} \\
(0.054)\end{array}$ \\
\hline Observations & 183 & 183 & 183 & 183 & 156 & 156 \\
\hline
\end{tabular}

Post-Lasso estimates. - indicates variable was excluded by the MI-LASSO procedure.

Note: Standard errors reported in parentheses. ${ }^{* * *}$ indicates $1 \%$ significant, ${ }^{* *} 5 \%$ significant and $* 10 \%$ significant. 


\subsection{Counterfactual estimates}

One reason to undertake an estimation exercise like ours is to provide estimates of the consequences of global changes in trade facilitation policies (through the TFA, for example). In general we have found that the available indicators can be well explained by other variables that are largely independent of the TFI variables we study. Although our cross-sectional model should not be understood as causal, our results may suggest some limits to the efficacy of the TFA in raising customs performance.

The one robust result we found across our estimates was that countries with better TFI scores related to procedures appear to have substantially smaller total import times, as measured by the TAB. The quantitative implications of this lesson can be drawn out through counterfactual analysis. We conduct an analysis where we move all countries to a maximal TFI score of '2' for the procedures variable. This implies an improvement for every country, as the TFI reports a maximum value of $1.87 .^{51}$ We apply the changes to the procedures variable to the estimated coefficient in Table 6 to calculate predicted changes in log points. Since the predicted changes are too large for the log approximation to be useful, we calculate the change in expected import time using the exponentials of predicted log import times, with and without an improvement in the procedures variable. With that approach, we calculate that a worldwide improvement in the TFI procedures variable would generate (on average) a reduction in total import times of $57 \%$. Recognizing that the coefficient estimate applied here coexists with a statistically significant coefficient of the opposite sign on the internal cooperation variable, we also conduct a joint exercise where we raise TFI scores for both policies to 2 . This exercise returns a smaller average reduction in total import times of $37 \% .{ }^{52}$

\section{Conclusion}

The large sums of international development aid that support trade facilitation initiatives make effective monitoring of progress an important objective. While impact evaluation of customs reforms offer the opportunity to better understand causal relationships between specific reforms and tangible outcomes in specific locations, formal impact evaluations are costly and difficult to accomplish in this policy space. Higher level monitoring of the implementation of the TFA and its impacts on the performance of national customs and trade logistics systems will need to rely on more aggregated

\footnotetext{
${ }^{51}$ One component of the TFI procedures variable is the existence of a single window for international trade, which does not yet exist in the US, for example, despite a years-long multi-agency effort.

${ }^{52}$ These estimates may seem large, but it is important to note that for most developed countries TAB reports total import times of 2 hours or less.
} 
(and less perfect) data. In this study we attempt to better understand (cross-country) empirical relationships between data on trade facilitation policies and a variety of outcomes that we label customs performance.

A key econometric problem in our data reveals a real world problem that may limit the impacts of reform. A country's trade facilitation policies are correlated strongly with other aspects of its civic and economic life that are difficult to change. Trade facilitation policies are better in countries with higher incomes and with better governing institutions. This is especially true of particular trade facilitation policy bundles. From an econometric point of view, the multi-collinearity problem makes it difficult to establish a direct effect of policy on customs performance that is separate from the effects of other variables that are not directly subject to change via the TFA. For example, it is unlikely that the TFA disciplines on appeal procedures are sufficient to improve governance more generally. Insofar as these more general country characteristics matter for customs performance they may limit the impacts of the TFA.

The available policy data are imperfect, and we adopt multiple imputation techniques to predict missing data points in a way that is compatible with rigorous statistical inference. This has the added benefit of informing the policy situation in countries where data collection is challenging. In order to address the multi-collinearity problem we adopt a LASSO estimator that accomodates multiple imputation. The estimates from this procedure retain a high degree of explanatory power, despite discarding many of the independent variables.

We study six outcome variables taken from two World Bank efforts to measure customs and trade logistics performance. The Logistics Performance Index (along with one of its subcomponents specifically designed to measure customs performance) appears to be largely determined by country characteristics and by measures of the quality of national governance. The governance indicators are quite strongly correlated with trade facilitation policy variables, and we are unable to observe a separate effect of policy variation on the LPI. Data from the Trading Across Borders survey are largely explained by levels of development, trade openness, geography, and trade agreements. On the import side, we observe some effects of policy on the TAB data, even after conditioning on other variables in the model. Countries with simpler procedures have lower import times across several robustness checks. Most other estimated links of policy to performance outcomes are statistically insignificant.

The one robust relationship in our estimates is a prediction that better import procedures gener- 
ate lower reported time to import. The coefficient estimate on the procedures variable is quite large and statistically significant across different estimating approaches. In order to better understand the quantitative implications of this result we calculate percentage changes in import times associated with all countries improving their procedures to best practice. The estimates suggest that this would generate sizable reductions in import times (in percentage terms).

\section{References}

Arvis, Jean-Francois, Daniel Saslavsky, Lauri Ojala, Ben Shepherd, Christina Busch, Anasuya Raj, and Tapio Naula (2016) 'Connecting to compete 2016: Trade logistics in the global economy.' World Bank Group report, International Bank for Reconstruction and Development / The World Bank

Belsley, David A., Edwin Kuh, and Roy E. Welsch (1980) Regression Diagnostics: Identifying influential data and sources of collinearity (New York, NY: John Wiley and Sons)

Beverelli, Cosimo, Simon Neumeuller, and Robert Teh (2015) 'Export diversification effects of the wto trade facilitation agreement.' FIW working Paper 137, Forschungsschwerpunkt Internationale Wirtschaft, January

Carballo, Jerónimo, Georg Schaur, Alejandro Graziano, and Christian Volpe Martincus (2016a) 'The border labyrinth: Information technologies in the presence of multiple agencies.' IDB Working Paper IDB-WB-706, Inter-American Development Bank

_ (2016b) 'Transit trade.' IDB Working Paper IDB-WB-704, Inter-American Development Bank

Carballo, Jerónimo, Georg Schaur, and Christian Volpe Martincus (2016c) 'Posts as trade facilitators.' IDB Working Paper IDB-WB-701, Inter-American Development Bank

_ (2016d) 'Trust no one: Security and international trade.' IDB Working Paper IDB-WB-703, InterAmerican Development Bank

Chen, Qixuan, and Sijian Wang (2013) 'Variable selection for multiply-imputed data with application to dioxin exposure study.' Statistics in medicine 32(21), 3646-3659

Djankov, Simeon, Caroline Freund, and Cong Pham (2010) 'Trading on time.' Review of Economics and Statistics 92(1), 166-73

Fan, Jianqing, and Runze Li (2001) 'Variable selection via nonconcave penalized likelihood and its oracle properties.' Journal of the American Statistical Association 96(456), 1348-1360

Fernandes, Ana M., Russell Hillberry, and Alejandra Mendoza Alcántara (2015) 'The effects of customs reform: Evidence from Albania.' Policy Research Working Paper 7210, World Bank Group, March

Fernandes, Ana M., Russell Hillberry, and Claudia Berg (2016) 'Expediting trade: Impact evaluation of an in-house clearance program.' Policy Research Working Paper 7708, World Bank Group, June

Fontagnét, Lionel, Gianluca Orefice, and Roberta Piermartini (2016) 'Making (small) firms happy. the heterogeneous effect of trade facilitation measures.' CEPII Working Paper 2016-08, CEPII, April 
Freund, Caroline, and Nadia Rocha (2011) 'What constrains Africa's exports?' World Bank Economic Review 25(3), 361-86

Hillberry, Russell, and Xiaohui Zhang (2015) 'Policy and performance in customs: Evaluating the WTO Trade Facilitation Agreement.' Policy Research Working Paper 7211, World Bank Group, March

Hoekman, Bernard, and Ben Shepherd (2013) 'Who profits from trade facilitation initiatives?' CEPR working paper 9490, Center for Economic and Policy Research, May

Hornok, Cecília (2012) 'Need for speed: Is faster trade in the EU trade creating?' Working Paper, Central European University

Hornok, Cecília, and Miklós Koren (2011) 'Lumpy trade and the welfare effects of administrative barriers.' CeFiG Working Papers 14, Center for Firms in the Global Economy

Horton, Nicholas J, and Stuart R Lipsitz (2001) 'Multiple imputation in practice.' The American Statistician 55(3), 244-254

Huang, Junzhou, Tong Zhang et al. (2010) 'The benefit of group sparsity.' The Annals of Statistics 38(4), 1978-2004

Kauffman, Daniel, Aart Kraay, and Massimo Mastruzzi (2010) 'The Worldwide Governance Indicators: Methodology and analytical issues.' Policy Research Working Papers 5430, World Bank

Kenward, Michael G, and James Carpenter (2007) 'Multiple imputation: current perspectives.' Statistical Methods in Medical Research 16(3), 199-218

Knight, Keith, and Wenjiang Fu (2000) 'Asymptotics for lasso-type estimators.' Annals of statistics pp. $1356-1378$

Li, Yue, and John Wilson (2009) 'Time as a determinant of comparative advantage.' World Bank Policy Working Papers 5128, World Bank

Martincus, Christian Volpe, Jerónimo Carballo, and Alejandro Graziano (2015) 'Customs.' Journal of International Economics 96(1), 119 - 137

Moïsé, Evdokia, and Silvia Sorescu (2013) 'Trade facilitation indicators: The potential impact of trade facilitation on developing countries' trade.' OECD Trade Policy Papers 144, OECD Publishing, March

Moïsé, Evdokia, Thomas Orliac, and Peter Minor (2011) 'Trade facilitation indicators: The impact on trade costs.' OECD Trade Policy Papers 118, OECD Publishing, August

Portugal-Perez, Alberto, and John S. Wilson (2012) 'Export Performance and Trade Facilitation Reform: Hard and Soft Infrastructure.' World Development 40(7), 1295-1307

Rubin, Donald B. (1976) 'Inference and missing data.' Biometrika 63(3), 581-592

Rubin, Donald B (1987) Multiple imputation for nonresponse in surveys (New York: Wiley)

Rubin, Donald B, and Nathaniel Schenker (1986) 'Multiple imputation for interval estimation from simple random samples with ignorable nonresponse.' Journal of the American Statistical Association 81(394), 366-374 
Saslavsky, Daniel, and Ben Shepherd (2014) 'Facilitating international production networks: The role of trade logistics.' The Journal of International Trade $\mathscr{E}$ Economic Development 23(7), 979999

Shepherd, Ben (2013) 'Trade times, importing and exporting: firm-level evidence.' Applied Economics Letters 20(9), 879-883

Stata (2013) Multiple-Imputation Reference Manual. Stata Press

Tibshirani, Robert (1996) 'Regression shrinkage and selection via the lasso.' Journal of the Royal Statistical Society. Series B (Methodological) 58(1), 267-288

Yuan, Ming, and Yi Lin (2006) 'Model selection and estimation in regression with grouped variables.' Journal of the Royal Statistical Society: Series B (Statistical Methodology) 68(1), 49-67

Zou, Hui, and Trevor Hastie (2005) 'Regularization and variable selection via the elastic net.' Journal of the Royal Statistical Society: Series B (Statistical Methodology) 67(2), 301-320 


\section{Appendix tables}

Table A1: OECD Trade Facilitation Indicators and their components.

\begin{tabular}{|c|c|}
\hline Indicator & Components \\
\hline $\begin{array}{l}\text { Information } \\
\text { availability }\end{array}$ & $\begin{array}{l}\text { 1. Customs has a web site. } \\
\text { 2. The rate of duty can be obtained through the customs web site. } \\
\text { 3. There are enquiry points to answer reasonable enquiries. } \\
\text { 4. It is possible to ask questions of the customs agency, specifically. } \\
\text { 5. There is enough information on procedures and required forms and documents. } \\
\text { 6. Some documents and forms can be downloaded from the website. } \\
\text { 7. There is an interval between the publication of new or amended trade related laws and regulations, } \\
\text { and their entry into force. } \\
\text { 8. Agreements with third countries about the above issues are published on the web site. } \\
\text { 9. Rules and examples of customs classification are publicly available. } \\
\text { 10. Transparency of government policymaking (GCR data). }\end{array}$ \\
\hline $\begin{array}{l}\text { Involvement } \\
\text { of the trade } \\
\text { community }\end{array}$ & $\begin{array}{l}\text { 1. Adequate and timely information on regulatory changes is provided (LPI data). } \\
\text { 2. The introduction or amendment of laws and regulations involves consultation with the private sector. } \\
\text { 3. Consultations are open to any interested party. } \\
\text { 4. Public comments are taken into account. }\end{array}$ \\
\hline Advance rulings & $\begin{array}{l}\text { 1. Advanced rulings are issued. } \\
\text { 2. There is a transparent online request procedure for advanced rulings. } \\
\text { 3. The number of requests for advanced rulings. } \\
\text { 4. Duration of the validity of the advanced ruling. } \\
\text { 5. Publication of average issuance times. } \\
\text { 6. Advance rulings of general interest are publicly available. } \\
\text { 7. It is possible to request a review of an advance ruling or its revocation / modification. } \\
\text { 8. Refusals to issue or revocations of advance rulings are explained/motivated. }\end{array}$ \\
\hline Appeal procedures & $\begin{array}{l}\text { 1. Appeal mechanisms exist and are explained on the Customs web site. } \\
\text { 2. There is possibility of judicial appeal in addition to the administrative appeal. } \\
\text { 3. The length of the time limit for appeals, if a limit exists. } \\
\text { 4. Information about the motives of the administration's decision is provided. } \\
\text { 5. Efficiency of legal framework in challenging regulations (GCR data). } \\
\text { 6. Judicial independence (GCR data). } \\
\text { 7. Equality of treatment of national and foreign actors (IPD data). } \\
\text { 8. Extent of implementation and speed of court rulings in commercial matters (IPD data). }\end{array}$ \\
\hline Fees and charges & $\begin{array}{l}\text { 1. Fees and charges are published on a web site. } \\
\text { 2. Fees and charges not related to the value of goods. } \\
\text { 3. Number and diversity of fees and charges (LPI data). } \\
\text { 4. There are no fees for Customs services during normal working hours. }\end{array}$ \\
\hline $\begin{array}{l}\text { Formalities } \\
\text { (Documents) }\end{array}$ & $\begin{array}{l}\text { 1. Customs and other border agencies accept copies of documents. } \\
\text { 2. Ratified international conventions on trade facilitation. } \\
\text { 3. Number of documents to prepare for import (DB data). } \\
\text { 4. Same for exports (DB data). } \\
\text { 5. Time necessary to prepare documents for import (DB data). } \\
\text { 6. Same for exports (DB data). }\end{array}$ \\
\hline $\begin{array}{l}\text { Formalities } \\
\text { (Automation) }\end{array}$ & $\begin{array}{l}\text { 1. Share of procedures that can be expedited electronically. } \\
\text { 2. Use of risk management. } \\
\text { 3. IT systems capable of handling electronic data exchange. } \\
\text { 4. Availability of full time }(24 / 7) \text { automated processing in Customs. } \\
\text { 5. Quality of telecommunications and IT (LPI data). }\end{array}$ \\
\hline $\begin{array}{l}\text { Formalities } \\
\text { (Procedures) }\end{array}$ & $\begin{array}{l}\text { 1. There is a single window. } \\
\text { 2. Average release times for large customs offices are published on a consistent and regular basis. } \\
\text { 3. Clearance time in days (LPI data). } \\
\text { 4. Pre-arrival processing is implemented. } \\
\text { 5. Share of physical inspections (LPI data). } \\
\text { 6. Perishable goods benefit from accelerated controls. } \\
\text { 7. Efficiency of customs for exports (LPI data). } \\
\text { 8. Efficiency of customs for imports (LPI data). } \\
\text { 9. Share of post-clearance audits carried out. }\end{array}$ \\
\hline
\end{tabular}


10. Separation of release from final determination and payment of Customs duties.

11. Perishable goods enjoy preferential treatment concerning the separation of release.

12. No pre-shipment inspection is required on Customs matters.

13. Authorized Operator (AO) programmes (LPI data)

14. Simplification of procedures (LPI data).

15. Simplification of procedures (DB data).

16. Working hours of Customs personnel are adapted to commercial needs.

17. Mandatory use of a third-party customs broker is not required.

\begin{tabular}{ll}
\hline Border agency & 1. Cooperation between domestic agencies on the ground (IPD data). \\
cooperation & 2. Government agencies delegate controls to Customs authorities. \\
(internal) & 3. Regular meetings are held to improve cooperation, and the private sector is included. \\
\hline Border agency & 1. Working days and hours are aligned with other neighboring countries. \\
cooperation & 2. Procedures and formalities are aligned with other neighboring countries. \\
(external) & 3. Common facilities are developed and shared with other neighboring countries. \\
& 4. There are joint controls with neighboring countries. \\
\hline Consularization & 1. The country does not impose consular transaction requirements. \\
\hline Governance & 1. Structures and functions of the Customs agency are publicly available. \\
& 2. A code of conduct is published and made available to all employees. \\
& 3. Information on disciplinary procedures and penalties for misconduct are publicly available. \\
& 4. Ethics policy is consistent with international norms and a help desk exists to guide staff on ethical issue \\
& 6. An audit function for internal systems is established, adequately empowered and operational. \\
& 7. Annual Customs reports are available and contain sufficient information on Customs activities. \\
& 8. Frequency of irregular payments and bribes (GCR data).
\end{tabular}

Notes: Adapted from Moïsé and Sorescu (2013) Annex 1. More detailed information is available there.

The OECD used some external data, attributed here with relevant abbreviations.

GCR data are from the Global Competitiveness Report published by the World Economic Forum.

$I P D$ data are from the Institutional Profiles Database compiled by CEPII.

LPI data are components of the domestic survey of the World Bank's Logistics Performance Index.

$D B$ data are components of the Doing Business - Trading Across Borders data.

Table A2: Broad product categories and associated HS2 codes

\begin{tabular}{ll}
\hline Broad sector & HS2-digit codes included \\
\hline Animal and vegetable products and foodstuffs & $1-24$ \\
Minerals & $25-27$ \\
Chemicals, plastics and rubbers & $28-40$ \\
Raw hides, skins, leathers, furs, textiles and footwear & $41-43,50-67$ \\
Wood and paper products & $44-49$ \\
Stone and glass & $68-71$ \\
Metals & $72-83$ \\
Machines and electrical & $84-85$ \\
Transportation & $86-89$ \\
Miscellaneous and services & $90-99$ \\
\hline Note: Product groupings for countries' largest (non-mineral) export commodity.
\end{tabular}


Table A3: TAB Import Time and Import Cost.

\begin{tabular}{|c|c|c|c|c|c|c|c|}
\hline & \multirow[t]{2}{*}{ Variables } & \multicolumn{3}{|c|}{ Import Time } & \multicolumn{3}{|c|}{ Import Cost } \\
\hline & & (1) & $(2)$ & $(3)$ & (4) & $(5)$ & (6) \\
\hline \multirow{11}{*}{ 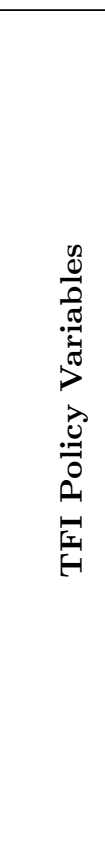 } & Information & $\begin{array}{c}1.803^{* * *} \\
(0.530)\end{array}$ & - & $\begin{array}{c}0.377 \\
(0.378)\end{array}$ & $\begin{array}{c}0.712^{* *} \\
(0.327)\end{array}$ & - & $\begin{array}{l}-0.112 \\
(0.256)\end{array}$ \\
\hline & Involvement & $\begin{array}{l}-0.401 \\
(0.459)\end{array}$ & - & $\begin{array}{l}-0.245 \\
(0.299)\end{array}$ & $\begin{array}{l}-0.166 \\
(0.284)\end{array}$ & - & $\begin{array}{l}-0.172 \\
(0.209)\end{array}$ \\
\hline & Advance Rulings & $\begin{array}{c}-0.940^{* *} \\
(0.367)\end{array}$ & - & $\begin{array}{c}-0.002 \\
(0.261)\end{array}$ & $\begin{array}{c}-0.709 * * * \\
(0.230)\end{array}$ & - & $\begin{array}{c}-0.034 \\
(0.178)\end{array}$ \\
\hline & Appeal & $\begin{array}{c}-1.001^{*} \\
(0.546)\end{array}$ & - & $\begin{array}{c}0.244 \\
(0.411)\end{array}$ & $\begin{array}{l}-0.413 \\
(0.339)\end{array}$ & - & $\begin{array}{l}-0.001 \\
(0.280)\end{array}$ \\
\hline & Fees \& Charges & $\begin{array}{l}-0.610 \\
(0.469)\end{array}$ & - & $\begin{array}{l}-0.347 \\
(0.309)\end{array}$ & $\begin{array}{c}-0.234 \\
(0.293)\end{array}$ & - & $\begin{array}{l}-0.195 \\
(0.212)\end{array}$ \\
\hline & Documents & $\begin{array}{c}0.533 \\
(0.719)\end{array}$ & - & $\begin{array}{l}-0.246 \\
(0.477)\end{array}$ & $\begin{array}{c}0.231 \\
(0.449)\end{array}$ & - & $\begin{array}{l}-0.280 \\
(0.327)\end{array}$ \\
\hline & Automation & $\begin{array}{l}-0.005 \\
(0.473)\end{array}$ & - & $\begin{array}{c}0.444 \\
(0.305)\end{array}$ & $\begin{array}{l}-0.170 \\
(0.296)\end{array}$ & - & $\begin{array}{l}-0.021 \\
(0.212)\end{array}$ \\
\hline & Procedures & $\begin{array}{c}0.037 \\
(0.754)\end{array}$ & - & $\begin{array}{c}-1.124^{* *} \\
(0.526)\end{array}$ & $\begin{array}{c}0.357 \\
(0.472)\end{array}$ & - & $\begin{array}{l}-0.246 \\
(0.363)\end{array}$ \\
\hline & Cooperation - internal & $\begin{array}{c}0.378 \\
(0.365)\end{array}$ & - & $\begin{array}{c}0.382 \\
(0.236)\end{array}$ & $\begin{array}{l}-0.027 \\
(0.229)\end{array}$ & - & $\begin{array}{l}-0.023 \\
(0.161)\end{array}$ \\
\hline & Cooperation - external & $\begin{array}{c}-0.352 \\
(0.280)\end{array}$ & - & $\begin{array}{c}0.241 \\
(0.190)\end{array}$ & $\begin{array}{l}-0.191 \\
(0.180)\end{array}$ & - & $\begin{array}{c}0.169 \\
(0.137)\end{array}$ \\
\hline & Governance & $\begin{array}{c}-1.689^{* * *} \\
(0.528)\end{array}$ & - & $\begin{array}{l}-0.062 \\
(0.344)\end{array}$ & $\begin{array}{c}-0.589^{*} \\
(0.326)\end{array}$ & - & $\begin{array}{c}0.370 \\
(0.240)\end{array}$ \\
\hline \multirow{9}{*}{ 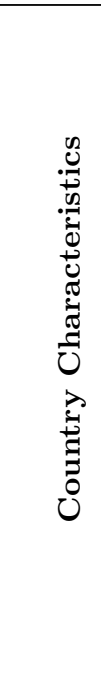 } & Openness & - & $\begin{array}{c}-0.691^{* *} \\
(0.307)\end{array}$ & $\begin{array}{c}-0.743^{* *} \\
(0.314)\end{array}$ & - & $\begin{array}{c}-0.490^{* *} \\
(0.204)\end{array}$ & $\begin{array}{c}-0.418^{*} \\
(0.216)\end{array}$ \\
\hline & GDP per capita & - & $\begin{array}{c}-1.801^{*} \\
(0.999)\end{array}$ & $\begin{array}{c}-2.247^{* *} \\
(1.089)\end{array}$ & - & $\begin{array}{c}-1.611^{* *} \\
(0.662)\end{array}$ & $\begin{array}{c}-1.663^{* *} \\
(0.742)\end{array}$ \\
\hline & $(\text { GDP per capita })^{\wedge} 2$ & - & $\begin{array}{c}0.107^{* *} \\
(0.061)\end{array}$ & $\begin{array}{l}0.125^{*} \\
(0.066)\end{array}$ & - & $\begin{array}{c}0.100^{* *} \\
(0.040)\end{array}$ & $\begin{array}{c}0.102^{* *} \\
(0.045)\end{array}$ \\
\hline & GDP & - & $\begin{array}{c}-0.051 \\
(0.130)\end{array}$ & $\begin{array}{c}-0.078 \\
(0.152)\end{array}$ & - & $\begin{array}{c}0.097 \\
(0.087)\end{array}$ & $\begin{array}{l}-0.110 \\
(0.103)\end{array}$ \\
\hline & Landlocked & - & $\begin{array}{c}1.124^{* * *} \\
(0.397)\end{array}$ & $\begin{array}{c}0.977^{* *} \\
(0.412)\end{array}$ & - & $\begin{array}{c}0.683^{* *} \\
(0.265)\end{array}$ & $\begin{array}{c}0.655^{* *} \\
(0.280)\end{array}$ \\
\hline & Island & - & $\begin{array}{l}0.683^{*} \\
(0.377)\end{array}$ & $\begin{array}{l}0.723^{*} \\
(0.378)\end{array}$ & - & $\begin{array}{c}0.398 \\
(0.250)\end{array}$ & $\begin{array}{c}0.376 \\
(0.256)\end{array}$ \\
\hline & WTO & - & $\begin{array}{l}-0.059 \\
(0.413)\end{array}$ & $\begin{array}{l}-0.374 \\
(0.435)\end{array}$ & - & $\begin{array}{c}0.107 \\
(0.273)\end{array}$ & $\begin{array}{l}-0.030 \\
(0.303)\end{array}$ \\
\hline & OECD & - & $\begin{array}{c}-2.631^{* * *} \\
(0.479)\end{array}$ & $\begin{array}{c}-2.912^{* * *} \\
(0.570)\end{array}$ & - & $\begin{array}{c}-1.390^{* * *} \\
(0.319)\end{array}$ & $\begin{array}{c}-1.714^{* * *} \\
(0.390)\end{array}$ \\
\hline & Land Area & - & $\begin{array}{c}0.168^{*} \\
(0.089)\end{array}$ & $\begin{array}{c}0.167^{*} \\
(0.093)\end{array}$ & - & $\begin{array}{l}0.111^{*} \\
(0.059)\end{array}$ & $\begin{array}{l}0.120^{*} \\
(0.063)\end{array}$ \\
\hline \multirow{5}{*}{ 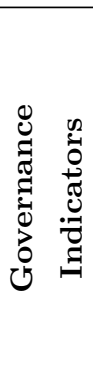 } & Corruption & - & $\begin{array}{c}0.161 \\
(0.444)\end{array}$ & $\begin{array}{c}0.131 \\
(0.463)\end{array}$ & - & $\begin{array}{c}0.210 \\
(0.299)\end{array}$ & $\begin{array}{c}0.204 \\
(0.322)\end{array}$ \\
\hline & Effectiveness & - & $\begin{array}{c}0.158 \\
(0.468)\end{array}$ & $\begin{array}{c}0.185 \\
(0.497)\end{array}$ & - & $\begin{array}{c}0.126 \\
(0.310)\end{array}$ & $\begin{array}{c}0.289 \\
(0.342)\end{array}$ \\
\hline & Stability & - & $\begin{array}{c}-0.571^{* *} \\
(0.245)\end{array}$ & $\begin{array}{c}-0.601^{* *} \\
(0.259)\end{array}$ & - & $\begin{array}{c}-0.373^{* *} \\
(0.164)\end{array}$ & $\begin{array}{c}-0.430 * * \\
(0.178)\end{array}$ \\
\hline & Reg quality & - & $\begin{array}{l}-0.273 \\
(0.365)\end{array}$ & $\begin{array}{l}-0.198 \\
(0.390)\end{array}$ & - & $\begin{array}{l}-0.238 \\
(0.243)\end{array}$ & $\begin{array}{l}-0.238 \\
(0.266)\end{array}$ \\
\hline & Voice & - & $\begin{array}{l}-0.268 \\
(0.222)\end{array}$ & $\begin{array}{l}-0.163 \\
(0.226)\end{array}$ & - & $\begin{array}{c}-0.019 \\
(0.148) \\
\end{array}$ & $\begin{array}{c}0.044 \\
(0.155) \\
\end{array}$ \\
\hline$\stackrel{0}{3}$ & Infrastructure & - & $\begin{array}{c}-0.930 \\
(1.181)\end{array}$ & $\begin{array}{c}-0.997 \\
(1.215)\end{array}$ & - & $\begin{array}{l}-0.183 \\
(0.776)\end{array}$ & $\begin{array}{l}-0.547 \\
(0.863)\end{array}$ \\
\hline : & $\mathrm{ICT}$ & - & $\begin{array}{c}-0.679 \\
(1.197)\end{array}$ & $\begin{array}{c}-0.016 \\
(1.296)\end{array}$ & - & $\begin{array}{c}0.019 \\
(0.831)\end{array}$ & $\begin{array}{c}0.299 \\
(0.967)\end{array}$ \\
\hline F & Bus. Environment & - & $\begin{array}{c}1.011 \\
(1.460)\end{array}$ & $\begin{array}{c}0.869 \\
(1.498)\end{array}$ & - & $\begin{array}{l}-0.140 \\
(0.985)\end{array}$ & $\begin{array}{l}-0.246 \\
(1.059)\end{array}$ \\
\hline
\end{tabular}




\begin{tabular}{|c|c|c|c|c|c|c|c|}
\hline 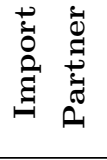 & $\begin{array}{l}\text { Land Border } \\
\text { PTA or CU }\end{array}$ & - & $\begin{array}{c}-3.045^{* * *} \\
(0.376) \\
-0.494^{*} \\
(0.272)\end{array}$ & $\begin{array}{c}-2.961^{* * *} \\
(0.394) \\
-0.586^{* *} \\
(0.286)\end{array}$ & - & $\begin{array}{c}-2.101^{* * *} \\
(0.250) \\
-0.258 \\
(0.180)\end{array}$ & $\begin{array}{c}-2.158^{* * *} \\
(0.271) \\
-0.260 \\
(0.196)\end{array}$ \\
\hline & Constant & $\begin{array}{c}4.912^{* * * *} \\
(1.168) \\
\end{array}$ & $\begin{array}{c}13.929^{* * *} \\
(4.652) \\
\end{array}$ & $\begin{array}{c}17.288^{* * *} \\
(5.089) \\
\end{array}$ & $\begin{array}{c}6.542^{* * * *} \\
(0.726) \\
\end{array}$ & $\begin{array}{c}14.637^{* * *} \\
(3.085) \\
\end{array}$ & $\begin{array}{c}15.655^{* * *} \\
(3.493) \\
\end{array}$ \\
\hline & R-square & 0.344 & 0.778 & 0.802 & 0.268 & 0.721 & 0.739 \\
\hline & Adj R-square & 0.302 & 0.753 & 0.763 & 0.221 & 0.689 & 0.688 \\
\hline & Observations & 183 & 183 & 183 & 183 & 183 & 183 \\
\hline
\end{tabular}

Note: Standard errors are reported in parentheses

$* * *$ indicates $1 \%$ significant, $* * 5 \%$ significant and $* 10 \%$ significant. 
Table A4: TAB Export Time and Export Cost.

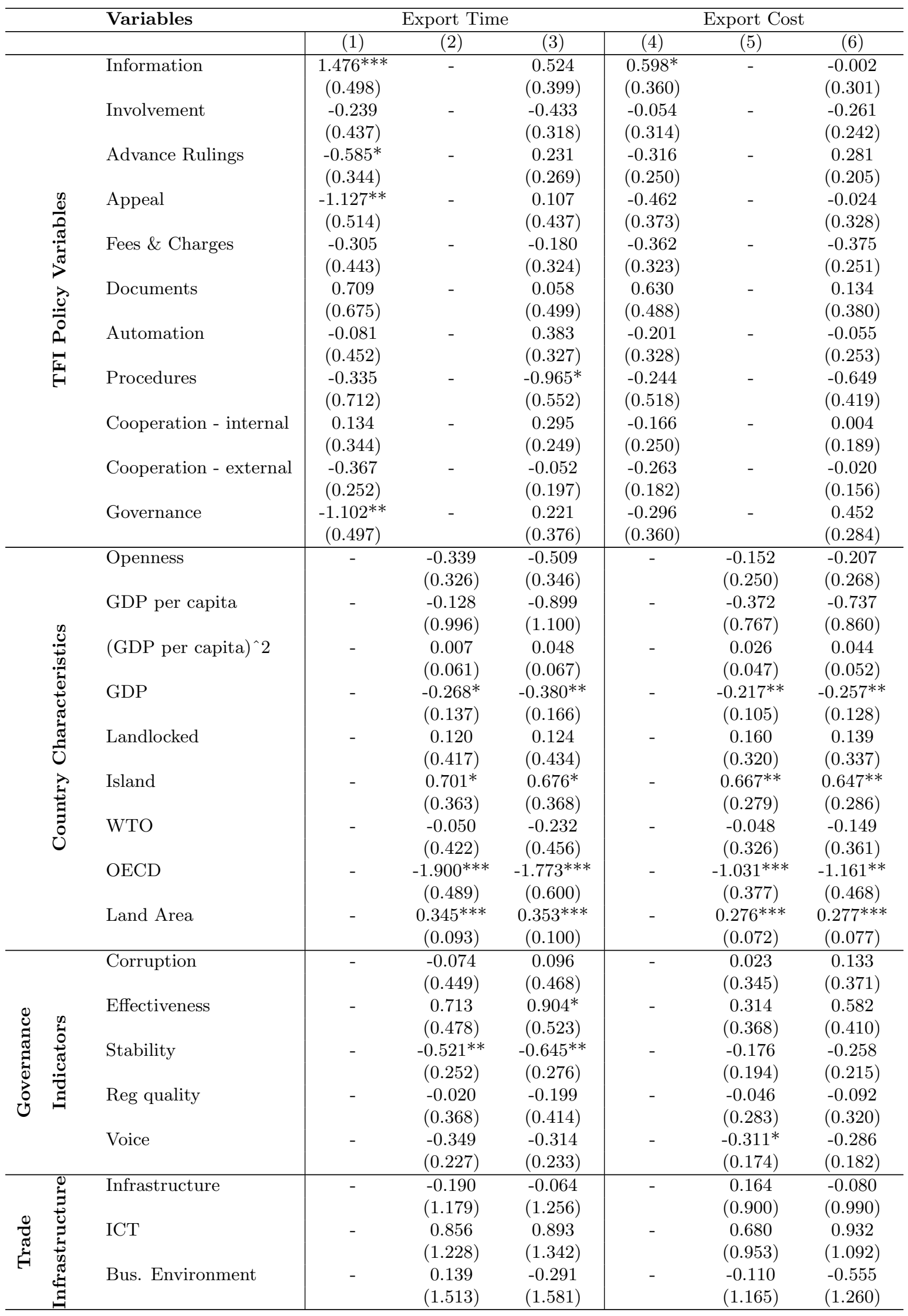




\begin{tabular}{|c|c|c|c|c|c|c|c|c|}
\hline 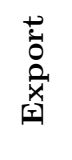 & $\begin{array}{c}\dot{0} \\
\dot{D} \\
\dot{0} \\
\dot{0}\end{array}$ & $\begin{array}{l}\text { Land Border } \\
\text { PTA or CU }\end{array}$ & - & $\begin{array}{c}-2.022^{* * *} \\
(0.370) \\
-0.758^{* * *} \\
(0.253)\end{array}$ & $\begin{array}{c}-2.168^{* * *} \\
(0.381) \\
-0.948^{* * *} \\
(0.276)\end{array}$ & - & $\begin{array}{c}-1.959^{* * *} \\
(0.285) \\
-0.307 \\
(0.195)\end{array}$ & $\begin{array}{c}-2.043^{* * *} \\
(0.297) \\
-0.415^{*} \\
(0.215)\end{array}$ \\
\hline & \multirow{19}{*}{ 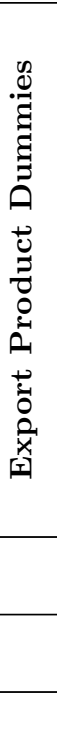 } & Animal/vegetable or & - & 0.601 & 0.057 & - & -0.444 & -0.596 \\
\hline & & Food & & $(1.096)$ & $(1.157)$ & & $(0.843)$ & $(0.902)$ \\
\hline & & Chem, Plast, Rubber & - & 0.064 & -0.330 & - & -0.814 & -0.936 \\
\hline & & & & $(1.123)$ & $(1.194)$ & & $(0.864)$ & $(0.928)$ \\
\hline & & Hides, skins, & - & 0.351 & -0.115 & - & -0.693 & -0.807 \\
\hline & & textiles\& footwr & & $(1.129)$ & $(1.176)$ & & $(0.868)$ & $(0.917)$ \\
\hline & & Wood Products & - & 0.269 & 0.005 & - & -0.664 & -0.850 \\
\hline & & & & $(1.383)$ & $(1.397)$ & & $(1.063)$ & $(1.092)$ \\
\hline & & Metals & - & 0.532 & 0.019 & - & -0.367 & -0.559 \\
\hline & & & & $(1.125)$ & $(1.199)$ & & $(0.865)$ & $(0.933)$ \\
\hline & & Mach. \& Elec & - & -0.713 & -1.174 & - & -0.935 & -1.083 \\
\hline & & & & $(1.105)$ & $(1.166)$ & & $(0.849)$ & $(0.907)$ \\
\hline & & Transport & - & -1.252 & -1.685 & - & -1.125 & -1.193 \\
\hline & & & & $(1.198)$ & $(1.281)$ & & $(0.921)$ & $(0.998)$ \\
\hline & & Constant & $4.561^{* * *}$ & 4.790 & $10.583^{*}$ & $6.276^{* * *}$ & $7.503^{* *}$ & $10.994^{* *}$ \\
\hline & & & $(1.080)$ & $(4.833)$ & $(5.439)$ & $(0.783)$ & $(3.710)$ & $(4.240)$ \\
\hline & & R-square & 0.284 & 0.732 & 0.758 & 0.195 & 0.669 & 0.692 \\
\hline & & Adj R-square & 0.238 & 0.688 & 0.696 & 0.144 & 0.614 & 0.613 \\
\hline & & Observations & 183 & 183 & 183 & 183 & 183 & 183 \\
\hline
\end{tabular}

Note: Standard errors are reported in parentheses.

$* * *$ indicates $1 \%$ significant, ${ }^{* *} 5 \%$ significant and * $10 \%$ significant. 
Table A5: LPI Measure (2016).

\begin{tabular}{|c|c|c|c|c|c|c|c|}
\hline & Variables & LPI & Measure $(\mathrm{C}$ & stom) & $\mathrm{LP}$ & Measure & All) \\
\hline & & (1) & $(2)$ & (3) & (4) & $(5)$ & (6) \\
\hline & Information & -0.051 & - & 0.006 & -0.042 & - & -0.004 \\
\hline & & $(0.048)$ & & $(0.042)$ & $(0.041)$ & & $(0.034)$ \\
\hline & Involvement & $0.089^{* *}$ & - & 0.030 & $0.070^{* *}$ & - & 0.014 \\
\hline & & $(0.040)$ & & $(0.033)$ & $(0.035)$ & & $(0.027)$ \\
\hline & Advance Rulings & -0.031 & - & $-0.044^{*}$ & -0.010 & - & -0.029 \\
\hline & & $(0.031)$ & & $(0.026)$ & $(0.026)$ & & $(0.021)$ \\
\hline$y$ & Appeal & $0.138^{* * *}$ & - & 0.049 & $0.144^{* * *}$ & - & 0.040 \\
\hline$\frac{0}{\pi}$ & & $(0.048)$ & & $(0.041)$ & $(0.041)$ & & $(0.033)$ \\
\hline$\stackrel{\infty}{\mathscr{*}}$ & Fees \& Charges & 0.061 & - & 0.013 & 0.036 & - & 0.003 \\
\hline$p^{\pi}$ & & $(0.039)$ & & $(0.032)$ & $(0.033)$ & & $(0.025)$ \\
\hline$\lambda$ & Documents & -0.060 & - & -0.014 & -0.031 & - & 0.006 \\
\hline$\stackrel{0}{0}$ & & $(0.059)$ & & $(0.049)$ & $(0.051)$ & & $(0.039)$ \\
\hline$\rho_{1}^{0}$ & Automation & 0.029 & - & -0.019 & 0.017 & - & -0.027 \\
\hline$\vec{F}$ & & $(0.043)$ & & $(0.033)$ & $(0.037)$ & & $(0.027)$ \\
\hline & Procedures & 0.092 & - & 0.018 & 0.050 & - & -0.002 \\
\hline & & $(0.060)$ & & $(0.051)$ & $(0.052)$ & & $(0.042)$ \\
\hline & Cooperation - internal & -0.014 & - & -0.041 & 0.003 & - & -0.028 \\
\hline & & $(0.032)$ & & $(0.026)$ & $(0.028)$ & & $(0.020)$ \\
\hline & Cooperation - external & 0.038 & - & 0.005 & $0.043^{* *}$ & - & 0.008 \\
\hline & & $(0.022)$ & & $(0.019)$ & $(0.019)$ & & $(0.015)$ \\
\hline & Governance & 0.073 & - & 0.006 & $0.086^{* *}$ & - & 0.026 \\
\hline & & $(0.046)$ & & $(0.037)$ & $(0.039)$ & & $(0.030)$ \\
\hline & Openness & - & 0.008 & 0.016 & - & 0.009 & 0.017 \\
\hline & & & $(0.031)$ & $(0.033)$ & & $(0.024)$ & $(0.026)$ \\
\hline & GDP per capita & - & $-0.296^{* * *}$ & $-0.328^{* * *}$ & - & $-0.195^{* *}$ & $-0.218^{* *}$ \\
\hline & & & $(0.096)$ & $(0.107)$ & & $(0.077)$ & $(0.086)$ \\
\hline$\stackrel{\circlearrowright}{\stackrel{U}{H}}$ & $(\text { GDP per capita })^{\wedge} 2$ & - & $0.015^{*}$ & $0.018^{* * *}$ & - & $0.010^{* *}$ & $0.012^{* *}$ \\
\hline$\stackrel{\sqrt[n]{2}}{=1}$ & & & $(0.006)$ & $(0.007)$ & & $(0.005)$ & $(0.005)$ \\
\hline$\underset{0}{0}$ & GDP & - & $0.029^{* *}$ & $0.029 *$ & - & $0.042^{* * *}$ & $0.040^{* * *}$ \\
\hline 菊 & & & $(0.013)$ & $(0.015)$ & & $(0.010)$ & $(0.012)$ \\
\hline త్రై & Landlocked & - & -0.037 & -0.045 & - & -0.015 & -0.025 \\
\hline$\vec{U}$ & & & $(0.036)$ & $(0.038)$ & & $(0.029)$ & $(0.031)$ \\
\hline$\partial$ & Island & - & -0.012 & -0.012 & - & -0.037 & -0.037 \\
\hline $\overrightarrow{\vec{Z}}$ & & & $(0.034)$ & $(0.034)$ & & $(0.027)$ & $(0.028)$ \\
\hline$\widetilde{0}$ & WTO & - & 0.004 & 0.004 & - & 0.019 & 0.017 \\
\hline & & & $(0.041)$ & $(0.045)$ & & $(0.032)$ & $(0.036)$ \\
\hline & OECD & - & 0.005 & -0.016 & - & -0.015 & -0.032 \\
\hline & & & $(0.043)$ & $(0.054)$ & & $(0.034)$ & $(0.044)$ \\
\hline & Land Area & - & -0.005 & -0.002 & - & -0.009 & -0.007 \\
\hline & & & $(0.008)$ & $(0.009)$ & & $(0.007)$ & $(0.007)$ \\
\hline & Corruption & - & 0.029 & 0.013 & - & -0.005 & -0.016 \\
\hline & & & $(0.043)$ & $(0.045)$ & & $(0.034)$ & $(0.036)$ \\
\hline & Effectiveness & - & 0.074 & 0.058 & - & $0.084^{* *}$ & $0.081^{*}$ \\
\hline 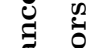 & & & $(0.047)$ & $(0.052)$ & & $(0.038)$ & $(0.042)$ \\
\hline శี & Stability & - & 0.021 & 0.016 & - & 0.007 & 0.000 \\
\hline 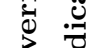 & & & $(0.023)$ & $(0.025)$ & & $(0.018)$ & $(0.020)$ \\
\hline 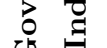 & Reg quality & - & $0.058^{*}$ & $0.070^{*}$ & - & 0.038 & 0.047 \\
\hline & & & $(0.034)$ & $(0.037)$ & & $(0.027)$ & $(0.030)$ \\
\hline & Voice & - & 0.004 & -0.002 & - & 0.020 & 0.016 \\
\hline & & & $(0.021)$ & $(0.022)$ & & $(0.017)$ & $(0.018)$ \\
\hline & Infrastructure & - & 0.043 & 0.029 & - & 0.021 & -0.003 \\
\hline 0.5 & & & $(0.115)$ & $(0.124)$ & & $(0.092)$ & $(0.100)$ \\
\hline T & ICT & - & 0.157 & 0.126 & - & 0.109 & 0.091 \\
\hline 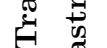 & & & $(0.136)$ & $(0.150)$ & & $(0.106)$ & $(0.115)$ \\
\hline$[\sqrt{4}$ & Bus. Environment & - & -0.163 & -0.104 & - & -0.030 & 0.002 \\
\hline$\Xi$ & & & $(0.145)$ & $(0.151)$ & & $(0.114)$ & $(0.119)$ \\
\hline
\end{tabular}




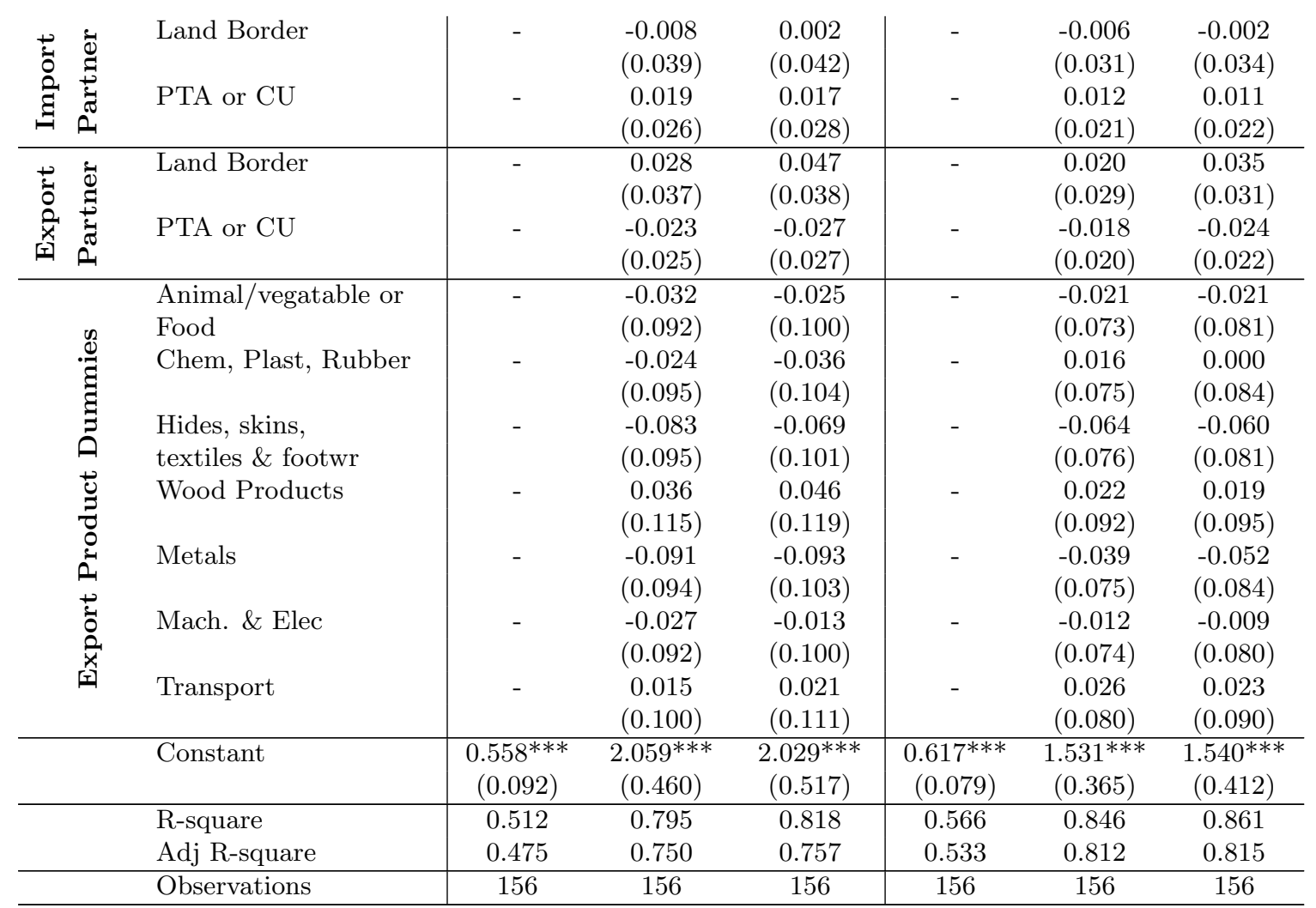

Note: Standard errors are reported in parentheses.

*** indicates $1 \%$ significant, ${ }^{*} * 5 \%$ significant and $* 10 \%$ significant. 